\title{
Molecular phylogenetics and evolutionary history of the endemic land snail genus Everettia in northern Borneo
}

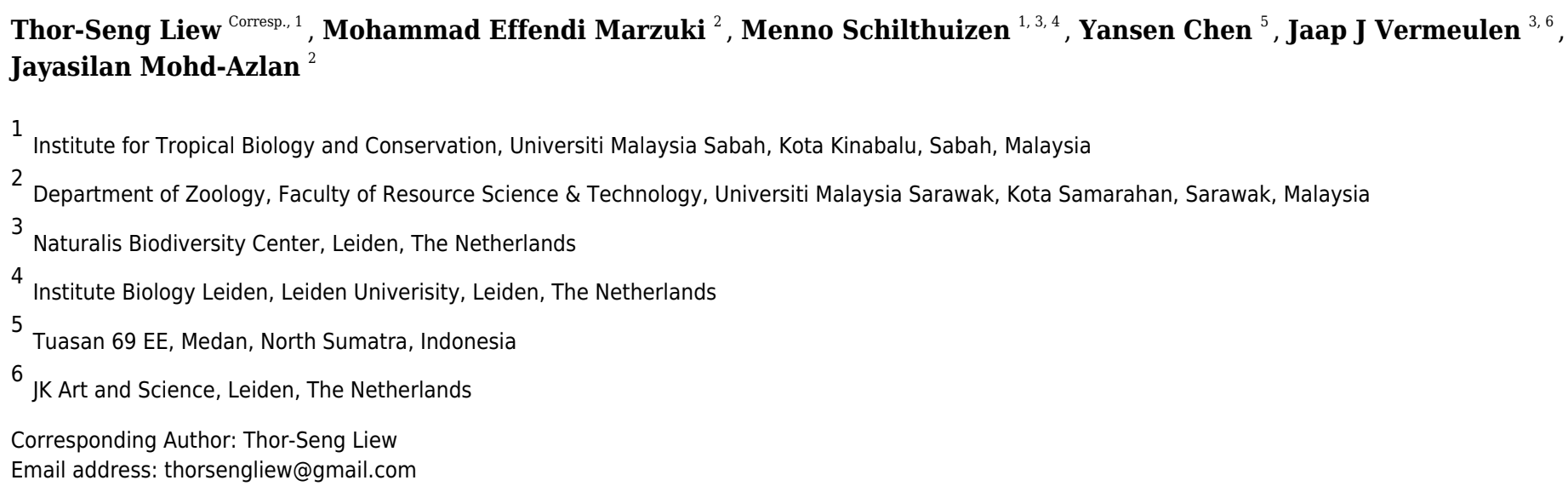

Borneo has gone through dramatic changes in geology and topography from the early Eocene until the early Pliocene and experienced climatic cycling during the Pleistocene. However, how these changes have shaped the present-day patterns of high diversity and complex distribution are still poorly understood. In this study, we use integrative approaches by estimating phylogenetic relationships, divergence time, and current and past niche suitability for the Bornean endemic land snail genus Everettia to provide additional insight into the evolutionary history of this genus in northern Borneo in the light of the geological vicariance events and climatic fluctuations in the Pleistocene. Our results show that northern Borneo Everettia species belong to two deeply divergent lineages: one contains the species that inhabit high elevation at the central mountain range, while the other contains lowland species. Species diversification in these lineages has taken place before the Pliocene. Climate changes during the Pleistocene did not play a significant role in species diversification but could have shaped contemporary species distribution patterns. Our results also show that the species-rich highland habitats have acted as interglacial refugia for highland species. This study of a relatively sedentary invertebrate supports and enhances the growing understanding of the evolutionary history of Borneo. Species diversification in Everettia is caused by geological vicariance events between the early Miocene and the Pliocene, and the distribution patterns were subsequently determined by climatic fluctuations in the Pleistocene. 


\section{Molecular phylogenetics and the evolutionary history of the} 2 endemic land snail genus Everettia in northern Borneo

4 Thor-Seng Liew ${ }^{1 *}$, Mohammad Effendi Marzuki², Menno Schilthuizen ${ }^{1,3,4}$, Yansen Chen ${ }^{5}$, 5 Jaap Jan Vermeulen ${ }^{3,6}$, Jayasilan Mohd-Azlan ${ }^{2}$

$7{ }^{1}$ Institute for Tropical Biology and Conservation, Universiti Malaysia Sabah, Kota Kinabalu, Sabah,

8 Malaysia

$9 \quad{ }^{2}$ Department of Zoology, Faculty of Resource Science \& Technology, Universiti

10 Malaysia Sarawak, Kota Samarahan, Sarawak, Malaysia

$11{ }^{3}$ Naturalis Biodiversity Center, Leiden, The Netherlands

$12{ }^{4}$ Institute of Biology Leiden, Faculty of Science, Leiden University, Leiden, The Netherlands

$13{ }^{5}$ Tuasan 69 EE, Medan, North Sumatra, 20222, Indonesia.

$14{ }^{6} \mathrm{JK}$ Art and Science, Leiden, The Netherlands.

16 Corresponding Author:

17 Thor-Seng Liew

18 Institute for Tropical Biology and Conservation, Universiti Malaysia Sabah, 88450 Kota Kinabalu, Sabah,

19 Malaysia

20 Email address: thorsengliew@gmail.com 


\section{Abstract}

25

26

27

28

29

30

31

32

33

34

35

36

37

Borneo has gone through dramatic changes in geology and topography from the early Eocene until the early Pliocene and experienced climatic cycling during the Pleistocene. However, how these changes have shaped the present-day patterns of high diversity and complex distribution are still poorly understood. In this study, we use integrative approaches by estimating phylogenetic relationships, divergence time, and current and past niche suitability for the Bornean endemic land snail genus Everettia to provide additional insight into the evolutionary history of this genus in northern Borneo in the light of the geological vicariance events and climatic fluctuations in the Pleistocene. Our results show that northern Borneo Everettia species belong to two deeply divergent lineages: one contains the species that inhabit high elevation at the central mountain range, while the other contains lowland species. Species diversification in these lineages has taken place before the Pliocene. Climate changes during the Pleistocene did not play a significant role in species diversification but could have shaped contemporary species distribution patterns. Our results also show that the species-rich highland habitats have acted as interglacial refugia for highland species. This study of a relatively sedentary invertebrate supports and enhances the growing understanding of the evolutionary history of Borneo. Species diversification in Everettia is caused by geological vicariance events between the early Miocene and the Pliocene, and the distribution patterns were subsequently determined by climatic fluctuations in the Pleistocene.

\section{Background}

Borneo, the third-largest island in the world, is one of the Earth's biodiversity hotspots (Mackinnon et al., 1996; Myers et al., 2000). Its biodiversity has been shaped by a long history of geological and climatic stability interspersed with periods of upheaval. During the Paleogene, east and north Borneo was submerged while the rest of Borneo was connected with other parts of Sundaland. Between Eocene and Pliocene, regional tectonic activities have caused the emergence of land and mountain building in Borneo (Hall, 2013), notably: the formation of highlands in central Borneo, the uplifting of Meratus Mountains in southern Borneo, and uplifting of Mount Kinabalu in northern Borneo. The erosion resulting from these mountainbuilding events have created the land in the northern, eastern, and southern parts of Borneo by filling large basins with sediment.

Borneo has been latitudinally stable, and a large part of it has been covered by tropical forest throughout this period (Lumadyo et al., 1993). Widespread evergreen rainforests would have covered much of Sundaland during the early and middle Miocene (de Bruyn et al., 2014). In the Pleistocene, rainforest persisting in some areas of the island were relatively little affected by climatic fluctuations as compared to other parts of Sundaland (Cannon et al., 2009; Wurster et al., 2010; Morley, 2012).

Hence, Borneo is a suitable natural laboratory for tropical evolutionary biology studies. Most of the studies of Borneo taxa have shown that Borneo was already a major evolutionary hotspot and centre of divergence in the pre-Miocene (see review by de Bruyn et al., 2014) or prePliocene (Nauheimer et al., 2012; Klaus et al., 2013; de Bruyn et al., 2014; Grismer et al., 2016; Williams et al., 2017; Chua et al., 2017; Chen et al., 2018). In addition, previous studies suggest that contemporary biodiversity richness and distribution patterns have been affected by climatic fluctuations in the Pleistocene (Barkman \& Simpson, 2001; Quek et al., 2007; Jalil et al., 2008; Patou et al., 2010; Lim et al., 2010, 2011; Ueda et al., 2010). 
68

69

70

71

72

73

74

75

76

77

78

79

80

81

82

83

84

85

86

87

88

89

90

91

92

93

94

95

96

97

98

99

100

101

102

103

104

105

106

107

108

109

110

111

112

Most of the previous studies use widespread organisms as model taxa to understand how historical processes shaped the genetic and diversity patterns. However, the genetic and diversity patterns of a well-dispersing taxon may be easily diluted and thus impede the interpretations of the events that shape the patterns (Beck et al., 2014; Manthey et al., 2017). Hence taxa that are relatively sedentary and narrowly distributed, and endemic to Borneo are potentially more suitable model organisms. Slow-moving land snails have proven to be excellent model species to understand evolutionary histories at different scales (Davison, 2002; Hugall et al., 2002), which is why we here employ an endemic land snail genus in the context of the historical biogeography of Borneo.

The taxonomy and distribution of the Bornean endemic land snail genus Everettia Godwin-Austen, 1891 has been well documented in northern Borneo (Liew et al., 2009). This genus is one of the most speciose macro land snails endemic to Borneo. It occupies different habitats from lowland tropical rainforest to highland montane forest, is found in intact forest, degraded forest, swampy forest, coastal forest, and islands. A large number of Everettia species are endemic to the highlands of Borneo, and many lowland species show disjunct distribution (Liew et al., 2009).

In this study, we aimed to provide a temporal framework for the diversification of the different lineages through the reconstruction of a time-calibrated multilocus species tree using relaxed clock models with species distribution modelling during the last glacial maximum (LGM). We examine whether species diversification in Borneo and highland diversity on Mount Kinabalu are either due to Pleistocene climatic fluctuation or earlier Tertiary paleogeographic events. First, we estimate the phylogeny of Everettia species in Borneo, including species from Sarawak and Kalimantan, by using mitochondrial and nuclear DNA, to elucidate the evolutionary history of Everettia in northern Borneo in the light of the key vicariance events. Second, we construct species distribution models for Everettia species in Sabah, where extensive occurrence data are available, to examine the changes of species distributions during the last glacial period and identify possible refugia during the last glacial maximum (LGM).

\section{Methods}

\section{Taxon sampling}

For molecular phylogenetic analysis, we included 71 Everettia specimens representing 16 of the 17 known species from Sabah. Besides, five Everettia species from Kalimantan and four Everettia species from Sarawak were also included (Table 1, Figure 1, Figure 2). The specimens were obtained from the following depositories: BORNEENSIS at Universiti Malaysia Sabah, the Sabah Parks Museum (SP), Jaap Jan Vermeulen's private collection (JJ), Leiden, Naturalis Biodiversity Center, Leiden (RMNH, ZMA), the Natural History Museum, London (BMNH), Mohammad Effendi Marzuki's private collection (ME), and Yansen Chen's private collection (YSC). Additional materials were obtained under the permits: Sarawak Forestry: NPW.907.4.4(Jld.14)-31), WL14/2017; and Sabah Parks: TS/PTD/5/4 Jld.54(112). For an outgroup taxon, we included two specimens of Quantula striata Gray, 1834, which belongs to the sister genus of Everettia within the family Dyakiidae.

For species distribution modelling, we obtained distribution records of Everettia species from the BORNEENSIS Molluscan collection that consists of 860 collection lots of Everettia species from Sabah that were collected between the years 2000 and 2018 (Figure 3, Figure 4, Figure 5, Figure 6). After excluding collection lots for which the exact location and species 
113 identity could not be determined, the final distribution data consists of 718 collection lots, which 114 comprise 2024 specimens of 17 Everettia species from Sabah (Additional File 1). The sampling

115 bias in the distribution data from BORNEENSIS collection is negligible as the entire surface of

116 Sabah has been covered adequately in terms of the geographical space, with some areas having

117 been sampled more densely due to the heterogeneity of the habitat such as mountain ranges and 118 islands (Figs. 3, 4, 5 and 6).

119

120

121

122

123

124

125

126

127

128

129

130

131

132

133

134

135

136

137

138

139

140

141

142

143

144

145

146

147

148

149

150

151

152

153

154

155

156

157

158

\section{Molecular methods}

Genomic DNA from approximately $2-3 \mathrm{~mm}^{3}$ of foot tissue of single individuals (either fresh, frozen, or kept in ethanol) was extracted with DNeasy ${ }^{\mathrm{TM}}$ nucleic acid extraction kits $\left(\mathrm{QIAGEN}^{\circledR}\right)$ and subsequently stored at $-20{ }^{\circ} \mathrm{C}$. Then, PCR was performed using a PTC-200 thermocycler (MJ Research, Inc.) or $\mathrm{T} 100^{\mathrm{TM}}$ Thermal Cycler (BIO-RAD) to amplify the mitochondrial DNA regions $16 S$ with the primer pair $16 \mathrm{Sbr}-\mathrm{L}$ and $16 \mathrm{Sbr}-\mathrm{H}$ (Palumbi et al., 1991), and COI with primers LCO1490 and HCO2198 (Folmer et al., 1994). Also, the nuclear rDNA region ITS- 1 was amplified with the primer pair 5.8c "silkworm" and 18d "fruitfly" (Hillis \& Dixon, 1991), and 28S with primers 28S1128 and 28S2119R (Uit de Weerd, 2008). PCR reactions were performed in $50 \mu \mathrm{l}$ volumes, using $5 \mu 110 \times$ reaction buffer (PROMEGA ${ }^{\circledR}$ or QIAGEN $\left.^{\circledR}\right), 5 \mu 12 \mathrm{mM}$ dNTP, $6 \mu 125 \mathrm{mM} \mathrm{MgCl}_{2}, 2 \mu \mathrm{l}$ for each primer (5 pmol), $26.85 \mu \mathrm{l}$ deionized autoclaved water and 1 unit of Taq polymerase (PROMEGA ${ }^{\circledR}$ or QIAGEN ${ }^{\circledR}$ ). Later, the following cycling profile was used: 2 min at $95^{\circ} \mathrm{C}$, followed by 35 cycles of $1 \mathrm{~min}$ at $95{ }^{\circ} \mathrm{C}, 1$ min at $55^{\circ} \mathrm{C}$ for $16 S, C O I$ and $28 S\left(60{ }^{\circ} \mathrm{C}\right.$ for ITS- 1$)$ and 2 min at $72{ }^{\circ} \mathrm{C}$, and a final extension period of $10 \mathrm{~min}$ at $72{ }^{\circ} \mathrm{C}$. Next, PCR-amplified DNA fragments were purified with the High Pure PCR Product Purification Kit (Roche ${ }^{\circledR}$ or ExoSAP-IT ${ }^{\circledR}$ ), according to the manufacturer's protocol. Finally, DNA sequencing was performed directly on purified PCR products in both directions using the BigDye Terminator Cycle Sequencing Kit v. 3.1 (Applied Biosystems Ltd), on an ABI 3100 Genetic Analyser (Applied Biosystems Ltd), by Macrogen ${ }^{\circledR}$ or the BigDye ${ }^{\circledR}$ Terminator v1.1, v3.0 and v3.1 Sequencing Kit on an Applied Biosystems 3730x1 DNA Analyser at MyTACG Biosciences Enterprise.

\section{Phylogenetic analysis}

A total of 96 genetic sequences of the previous study (Liew et al., 2009) and 160 new genetic sequences from the present study were aligned using the ClustalW multiple alignment algorithm in the BioEdit Sequence Alignment Editor, version 7.0 (Hall, 1999) and manually adjusted with the same program. Before the phylogenetic analyses, the data matrix was we partitioned by markers and codons of COI, namely, 1st, 2nd and 3rd codon positions of COI, $16 \mathrm{~S}$ rDNA, ITS-1, and 28S rDNA. Then, each of the partitions was tested for molecular evolution via ModelFinder (Kalyaanamoorthy et al., 2017) and partition models (Chernomor et al., 2016) based on the both AIC and BIC that built into IQ-Tree v.1.6.7 (Nguyen et al., 2015; Trifinopoulos et al. 2016). We limited the candidate models to the six models that are available in MrBayes analysis, namely, JC, F81, K80, HKY, SYM, and GTR. The results of ModelFinder and partition model suggested different partition schemes and substitution models for respective AIC and BIC selection criteria (Additional File 2). We explored the phylogenies estimated based on different substitution models selected for AIC and BIC but the resulted phylogenies are generally congruent (Additional File 3). Hence, we used the best-fit substation models and partition scheme of BIC selection: partition (1) $16 \mathrm{~S}+\mathrm{ITS}$ : GTR $+\mathrm{F}+\mathrm{G} 4$, partition (2) $\mathrm{COI} 1+\mathrm{COI} 2+28 \mathrm{~S}: \mathrm{SYM}+\mathrm{I}+\mathrm{G} 4$, and partition (3) $\mathrm{COI} 3: \mathrm{GTR}+\mathrm{F}+\mathrm{G} 4$.

Peer] reviewing PDF | (2019:09:41728:1:1:CHECK 15 May 2020) 
159

160

161

162

163

164

165

166

167

168

169

170

171

172

173

174

175

176

177

178

179

180

181

182

183

184

185

186

187

188

189

190

191

192

193

194

195

196

197

198

199

200

201

202

203

204

205

The sequences were analysed using Bayesian analysis (BA) with MrBayes 3.1 (Huelsenbeck \& Ronquist, 2001) at the CIPRES Science Gateway portal (Miller et al., 2010)and a maximum likelihood (ML) method implemented in IQ-Tree v.1.6.7 (Nguyen et al., 2015). For BA, the data matrix was analysed with 10 million generations and sampled every $1000^{\text {th }}$ generation. Then, we discarded the first $25 \%$ of the samples. BA was repeated three times for data matrix, and a consensus tree with a cut-off value of $50 \%$ was calculated for the resultant trees. For ML analysis, we estimated the phylogeny by using 1000 ultrafast bootstrap replicates (Minh et al., 2013).

\section{Estimation of divergence time}

BEAST 2 (ver. 2.6.1) (Drummond \& Rambaut, 2007) was used to estimate the timescale for Everettia species divergences based on selected samples for each species. We presume that the split between two Everettia species: E. sp. 1 and E. sp. 2, that occur at the two sides of the Meratus range in South Kalimantan based on a geological event - the uplift of the Meratus Range during late Miocene (10 Ma) (Hall, 2013). Hence, the hypothesis on the timing of speciation of the phylogeny is based on this calibration point which the divergence of the species has resulted from the uplifting of the mountain ranges in Borneo. The tools provided in BEAST 2 were used to estimate node ages to the most common recent ancestor (TMCRA) of the split and substitution rates.

We carried out four independent runs of 50,000,000 generations each, sampled every 10,000 generations, using calibrated Birth-Death model with best-fit GTR models, a relaxed lognormal molecular clock was employed, and default options for all other priors and operator settings. The Birth-Death model is chosen as we believe that the evolution of Everettia species a continuous-time process with a probability that a lineage will go extinct. We also explored the time divergence estimates for the combinations two different best-fit substitution models (selected by BIC and AIC criteria) and two calibrated models (Yule model vs Birth-Death model) and the results of these analyses are similar (Additional File 4). The output of each independent run was visualised in Tracer 1.4. Samples and trees from separate runs were pooled after removing the first $10 \%$ as burn-in using LogCombiner ver. 2.6 .1 and $10 \%$ of the trees were discarded as burn-in, and maximum clade credibility trees were calculated each from the remaining 180,004 trees using TreeAnnotator 2.6.0. Divergence dates were computed using BEAST 2 at CIPRESS. The geology-based calibration point $(10.0 \mathrm{Ma} \pm 0.5,95 \% \mathrm{CI})$ was taken as the central trend of a normally distributed prior in BEAUti.

\section{Ecological-niche modelling}

To understand how the distribution of Sabah Everettia species has changed during the paleoclimatic fluctuations in the Pleistocene, we predicted ecological niches for all eighteen Sabah Everettia species by using current distribution data under the contemporary (i.e. interglacial) and past (i.e. glacial) climatic conditions. As in other land snail studies (Hugall et al., 2002), we assumed niche conservatism for Everettia.

For the environmental data, we used the bioclimatic dataset version 1.4 (http://www.worldclim.org/current; Fick \& Hijmans, 2017). Each of the current bioclimatic layers of resolution of 30 arc-seconds was clipped to the extent of Borneo. After that, we sampled bioclimatic variables for 500 random locations in Borneo to evaluate the collinearity among the 19 climatic variables by using pairwise Pearson's $r$ correlation (Additional File 5). After we removed highly correlated variables $(r>0.8)$, a total of seven climatic variables were

Peerj reviewing PDF | (2019:09:41728:1:1:CHECK 15 May 2020) 
206

207

208

209

210

211

212

213

214

215

216

217

218

219

220

221

222

223

224

225

226

227

228

229

230

231

232

233

234

235

236

237

238

239

240

241

242

243

244

245

246

247

used for species distribution modelling, namely, BIO1 Annual Mean Temperature, BIO3 Isothermality, BIO4 Temperature Seasonality, BIO7 Temperature Annual Range, BIO12 Annual Precipitation, BIO15 Precipitation Seasonality, and BIO19 Precipitation of Coldest Quarter. Next, the corresponding seven bioclimatic variables of the paleoclimatic dataset for the last glacial maximum (LGM, model CCSM; http://www.ccsm.ucar.edu/, Kiehl \& Gent, 2004) were resampled at resolutions of 30 arc-seconds $\left(\sim 1 \mathrm{~km}^{2}\right)$.

Then, MaxEnt software (ver. 3.4.1, Phillips et al., 2006; Phillips \& Dudík, 2008) was used to generate logistic probability maps of species presence with logistic values ranging from 0 (unsuitable) to 1 (optimal habitat). The model was run using the following settings: the maximum number of background points $=10,000$; replicates $=10$; and replicate run type - Cross validate. All other parameters were kept at default values. Finally, the average of the logistic probability of species occurrence for each grid cell was calculated from the resultant ten replicates.

\section{Results}

\section{Phylogenetic Analyses}

The combined mitochondrial and nuclear DNA matrix comprises 73 specimens and 2795 characters (16S: 1-501; COI: 502-1059; 28S: 1060-1869; ITS: 1870-2795 (Additional File 6). The best nucleotide substitution models are reported in Additional File 2. As revealed by the Bayesian posterior probability (PP) and maximum likelihood analysis bootstrap (BS) values of the phylogenetic tree in Figure 7, most of the species are monophyletic, and phylogenetic relationships between species are similar to those found in a previous study (Liew et al., 2009).

In contrast to the previous study (Liew et al., 2009), this study shows the phylogenetic relationship of Sabah Everettia species in the broader context of Bornean Everettia species. Everettia species of Sabah do not form a monophyletic group, and belong to four independent lineages, namely: lineages A, C, D, and E (Fig. 7). The other lineage B consists of one species from Sarawak near the border with Brunei and two species from South Kalimantan. However, some of the phylogenetic relationships among these lineages are poorly supported by Bayesian analysis (i.e. PP $<0.95$ ) (Fig.7).

A total of 12 out of 16 Everettia species in Sabah belong to two major lineages. The first lineage (hereafter, lineage A) consists of nine species, seven of which are lowland species that have their lowest elevation distribution below $1000 \mathrm{~m}$, namely E. subconsul, E. interior, E. paulbasintali, and E. jucundior from Sabah (Figs, 5, 6, and 7); E. algaia from Sarawak; E. sp. 4 and $E$. sp. 5 from East Kalimantan (Figure 1). Two of the species of this lineage $(E$. layanglayang and $E$. themis) have their lowest elevational distribution below $2000 \mathrm{~m}$ (Figs. 4 and 7). With this expanded genetic dataset, E. themis is now paraphyletic to E. subconsul.

The second lineage (hereafter, lineage C) consists of eight species, of which four are Mount Kinabalu endemics with a lowest elevational limit above $2000 \mathrm{~m}$, namely E. jasilini, E. safriei, E. corrugata corrugata, and E. c. williamsi (Figs. 3 and 7); two are highland species with their lowest elevation above $1000 \mathrm{~m}$, namely E. monticola and E. dominiki; and a further two are lowland species: E. planispira from Sabah and E. sp. 3 from Central Kalimantan which occur more than $600 \mathrm{~km}$ apart from each other (Figs. 1 and 6). 
The remaining four Sabah Everettia species, namely E. jucunda, E. klemmantanica, E. lapidini, and E. jucundior, do not belong to the lineages A and C. The Sabah Everettia jucunda form a lineage with an Everettia species (sp. 6) from Sarawak. The Sabah and Sarawak species are more than $500 \mathrm{~km}$ apart from each other (lineage E, Fig. 7). E. lapidini and E. klemmantanica are not shown as mutually monophyletic species but as a joint monophyletic clade (lineage D, Fig. 7).

The lineage B consists of two Everettia species from South Kalimantan (sp. 1 and sp. 2) and E. baramensis from Sarawak. The Sarawak and South Kalimantan species are more than 700 $\mathrm{km}$ apart from each other (lineage B, Fig. 7). Lastly, E. sp. 7 from Sarawak does not form a clade with any other Everettia species.

\section{Divergence time and tempo of speciation}

Here, we used only one calibration point based on a single biogeographic event given the limited availability of fossil records, and reasonable estimates of mutation rates across different genes for the land snail taxa in this region. Currently, the only known land snail fossils in Southeast Asia are from species of Family Cyclophoridae that cannot be used for calibration in this study (Raheem et al., 2018; Xing et al., 2019). The topography of the chronogram is generally congruent with the phylogenetic analysis, of which most of the deeper nodes are poorly supported (PP < 0.95) (Figs. 6 and S1). Our results show the divergences among Everettia in various areas of Borneo are tally to the area's major mountain uplifting events. These divergence time estimates are based on the hypothesis that mountain uplifting events caused the divergence of the two Everettia species at the two sides of the Meratus range could be falsified in the future if there are more accurate vicariance geological events or reliable fossil record available to improve the calibration of the phylogeny. . Diversification of Everettia species in Borneo began in the Late Oligocene $(25.8 \mathrm{Ma})$. These species diversified into five major lineages between the early Miocene (23 Ma - $17 \mathrm{Ma}$ ). The lowland lineage (lineage A) diversified rapidly into seven species between $7 \mathrm{Ma}$ and $19 \mathrm{Ma}$ (Figs 8 and S1). The highland lineage (lineage C) diversified rapidly into montane species and the Mount Kinabalu endemics lineage between $4 \mathrm{Ma}$ and 15 (Figs 8 and S1). Deep divergence of the South Kalimantan and Sarawak species is seen in lineage B (17 Ma).

\section{Comparison of the ecological-niche model of contemporary and past distribution}

Distributional range shifts of Everettia species during the LGM are predicted by the habitat suitability maps in Figures 3, 4, 5, and 6. As shown in the phylogenetic analysis, $E$. themis is now considered as E. subconsul for species distribution modelling (Fig. 7). The area under the curve (AUC) values for the 15 species models are higher than 0.85 , except $E$. klemmantanica.

Most of the Sabah Everettia species have their suitable habitat in Sabah, particularly the endemic species on Mount Kinabalu and central mountain ranges in Sabah. The analysis suggests that suitable habitats for E. jucundior, E. planispira, and E. interior are not limited to Sabah, but are extended to large areas in the eastern and southern part of Borneo. Besides, small areas of suitable habitats for E. paulbasintali, and E. occidentalis are located in the eastern part of Borneo. 
The palaeoclimatic models predict contraction and expansion of suitable habitats during the LGM for different Everettia species. All four Mount Kinabalu endemic species (Everettia corrugata corrugata, E. c. williamsi, E. jasilini, and E. safriei) have experienced range expansion during the LGM at the central mountain range of Sabah. Highland species $E$. dominiki, E. monticola, E. layanglayang, and E. lapidini experienced range expansion as Mount Kinabalu endemics and also in the mountain ranges in the western Borneo.

$E$. planispira, the lowland relative of E. dominiki and E. monticola - - experienced significant range expansion in eastern and southern Borneo. Phylogenetic analysis suggests that E. planispira is the sister taxon for E. sp. 3, which is found in southern Borneo. A few of the lowland species, viz. E. paulbasintali, E. occidentalis, E. jucunda, and E. jucundior, experience range contraction and probably remain with very limited suitable habitats. E. subconsul was predicted to have experienced a shrinking of suitable habitat during the LGM into areas near the tip of northern Borneo, including offshore islands and lowland around Mount Kinabalu. Phylogenetic analysis also showed that the populations of E. subconsul on northern offshore islands and tips of northern Borneo are the oldest for the species.

The other lowland species E. interior experienced a little reduction of suitable habitats and its contemporary distribution range is similar to that during the LGM. In particular, the contemporary distributional range of $E$. interior could potentially extend to eastern Borneo.

\section{Discussion}

A high species diversity and high degree of endemism in northern Borneo are well known for many plant and animal taxa, particularly for the central mountain ranges, i.e., the Crocker Range, Mount Kinabalu and the Trusmadi Range (Liew et al., 2009; Beaman, 2005). Land snail studies in other regions suggest that vicariance events that persist long enough play crucial roles in driving radiation (Douris et al., 1998; Parmakelis et al., 2005; Fiorentino et al., 2010; Pfenninger et al., 2010; Rowson et al., 2011), with other factors such as dispersal events and niche differentiation causing further modification (Douris et al., 1998; Schilthuizen et al., 2004; Hausdorf \& Hennig, 2004, 2006; Holland \& Cowie, 2009; Ketmaier et al., 2010; Kokshoorn et al., 2010). Previously, the phylogeny of Everettia species was estimated without other congener species from outside of Sabah (Liew et al., 2009). Although species sampling outside of Sabah is still far from complete, these additional species from part of Borneo provides a more accurate phylogeny to illustrate the evolution of Sabah Everettia species that are more or less completely sampled reveal several novel insights.

\section{Divergence of species in the highland lineage}

First, most of the Sabah species belong to two deeply diverged lineages. One lineage mainly consists of highland species, particularly all endemics of Mount Kinabalu, while the other lineage includes lowland species. The divergence of these two lineages took place during the early Miocene, which coincided with the uplift of mountain ranges and an extended land area from the southwest to the northeast of the centre of Borneo (Figure 8). Hence, the divergence was not caused by the more recent uplift of Mount Kinabalu as postulated by studies on other organisms (O'Connell et al., 2018). 
372

373

374

375

376

377

378

379

380

381

The diversification of the four Kinabalu endemics (E. jasilini, E. safriei, E. corrugata corrugata, and E. c. williamsi) within the highland lineage happened after the middle Pliocene (after 3.8 Ma), and could have been caused by the uplifting of Mount Kinabalu (Figs. 3 and 4). The rapid uplift of Mount Kinabalu at the rate of 500 meters per million years (Cottam et al. 2010) could have caused allopatric speciation when the habitat at higher elevation arose, and populations were isolated (Merckx et al, 2015). However, the remaining three species $(E$. monticola, E. dominiki and E. layanglayang) that reach to an elevation of $3000 \mathrm{~m}$ on Mount Kinabalu and are sympatric with the four Kinabalu endemics more likely diverged by geographical isolation on other mountain summits and subsequently became secondarily sympatric (judged by their deep divergence, before the emergence of Mount Kinabalu).

The paleo-distributions during the LGM of these seven species provide some insights that these species had more widespread distribution ranges in the central mountain ranges of Borneo that are adjacent to Sabah, based on the suitable habitat analysis (Figs. 3 and 4). This suitable habitat may have facilitated dispersal of these once geographically isolated highland species between Central and northern Borneo montane areas when the cooler temperature during the LGM caused the montane forest to descend and spread, which would have increased connectivity among mountains (e.g. Manthey et al., 2017).

However, habitat at lower elevations became hostile to these highland lineage species when the climate warmed up during interglacials. These species probably reacted by moving to suitable habitat at higher altitudes or went extinct altogether. Thus, we believe that Mount Kinabalu has served as a refugium during interglacial periods for highland Everettia species. These highland species could have been trapped there during several glaciation cycles, although we cannot say at which Quaternary glaciation stages this happened. Furthermore, we have shown that land snails on other northern Bornean mountains also show shorter ranges at higher elevations compared to the lowland and lower montane areas (Liew et al., 2010), indicating that these species have been pushed upwards until the end of their optimum habitat. This finding supports the studies of other taxa that proposed the mountain ranges in Sabah play a role in the maintainance of ancient lineages (Sheldon, 2017).

The discrepancy of the two divergent processes for the sympatric species on top of Mount Kinabalu provides additional insight that challenge the conventional view that Mount Kinabalu acted as a 'speciation pump' and that lower elevation ancestors gave rise to high-elevation endemics (e.g., Lee et al., 1980; de Laubenfels, 1988; Holloway, 1996; Chan \& Barkman, 1997; Barkman \& Simpson, 2001; Tanaka et al., 2001).

\section{Divergence of species in the lowland lineage}

Sabah became fully emergent only at the end of the Miocene or Early Pliocene. Two of the most widespread lowland species in Sabah - E. subconsul and E. paulbasitali from lineage A, rapidly colonized newly emerged habitat. Although we did not perform analysis on different populations of other lowland species, we think it is very likely the other widespread lowland species, for example E. jucundior and E. planispira, dispersed to the newly formed land at the same time. In addition to the role_of Mount Kinabalu as an interglacial refugium for highland lineage species, SDM analysis shows that Mount Kinabalu also acted as a glacial refugium for 
382 lowland lineage species, for example E. subconsul. northern Borneo has been mentioned as a 383 probable glacial refugium during climate changes in the Pleistocene (Brandon-Jones, 1996, 384 1997; Gathorne-Hardy et al., 2002), but the exact locations of suitable refugia have remained

\section{Conclusions} unknown, with some hypothesizing that Mount Kinabalu and the Crocker Range could have played such a role (Cockburn, 1978; Smith, 1980; Quek et al., 2007; Jalil et al., 2008). Our study identifies two probable glacial refugia for E. subconsul, on the east and west slopes of Mount Kinabalu. These two glacial refugia, together with unsuitable habitat and mountain ranges as geographical barriers in the centre of northern Borneo, could explain how the east and west coast populations of E. subconsul have maintained their deeply diverged origin since the late Miocene (Figs. 8 and 6).

In contrast to the distribution patterns in the highland lineage, most of the species in lowland lineage occur allopatrically, with the exception of E. subconsul, E. paulbasintali, E. planispira, and E. jucundior which are sympatric on the east coast of Sabah. At first glance, the allopatric distributions of the lowland Everettia species appear to be due to geographical isolation caused by mountain ranges, as has been suggested in studies on other taxa (e.g., Bänfer et al., 2006). Besides, distribution patterns of lowland species are similar to physiography, vegetation, and biozoographical subregions of northern Borneo (Collenette, 1963; Mackinnon \& Mackinnon, 1986; Mackinnon et al., 1996; Wong, 1998).

Based on the paleo-distribution analysis, the lowland species mostly expanded postglacially, whereas the ranges of the highland species are currently contracting by moving to higher elevations. These different responses by highland and lowland land snails to climate fluctuations are also known from other tropical regions (Wronski \& Hausdorf, 2008). Hence, Mount Kinabalu acts as interglacial and glacial refugium for remnant populations, which results in a species diversity hotspot. In Everettia, a total of thirteen out of seventeen northern Borneo species occur on Mount Kinabalu, and six of those species are endemic. The high richness of ancient species agrees with the fact that northern Borneo has had a stable ever-wet climate with most of the forest persisting over the glaciations (Bird et al., 2005: Wurster et al., 2010). northern Bornean populations or taxa are known to have been isolated from other parts of Borneo, especially western Borneo, in rainforest refugia during the Pleistocene (Moyle et al. 2005, 2011, 2017: Sheldon et al. 2015).

Our data enhance the understanding of the evolutionary history of northern Borneo. The northern Borneo Everettia species belong to two deeply diverged lineages. The ecological differentiation and divergence of these two lineages were caused by the uplift of mountain ranges in central Borneo during the Miocene. The continuing eastward and northward extension of Borneo land area together with the formation of central mountain ranges in these newly emerged parts of Borneo have probably driven the species diversification of Everettia in both lineages throughout the Miocene. The species distributional ranges have changed during fluctuating climatic conditions in the Pleistocene. The highland species tended to expand their distribution ranges and lowland species distributional ranges retracted in response to glacial periods, and vice versa during interglacials. We also show that the central mountain ranges of northern Borneo, especially Mount Kinabalu, have acted as refugia in both interglacial and glacial periods. Thus, 
427 the contemporary species richness and endemism are caused by geological vicariance events 428 while the contemporary species diversity and distribution patterns are shaped by the Pleistocene 429 climatic fluctuations. We also provide a scenario for how these mountain ranges may have

\section{Acknowledgements}

436 We thank Jamili Nais, Reuben Clements, and Raes Niels for fruitful discussions. We thank research staff and mountain guides of from the Research and Education Division of Sabah Parks for their field assistance. We are grateful to Maklarin Lakim, Lam Nyee Fan, Noramly Muslim, and Monica Suleiman for providing logistics for field trips and genetic analyses. Wim Maassen

440

441 (RMNH), Fred Naggs (BMNH), Jonathan Ablett (BMNH), Robert Moolenbeek (ZMA), and Martinah Latim (SP) provided help during our visits to their respective institution collections. We appreciate constructive comments from Nikolay Poyarkov, Frank Koehler and an anonymous reviewer during the peer review.

\section{Supplemental Information}

Additional File 1. Species records of Genus Everettia in Sabah for Maxent Analysis. The table consists of the 718 records of 17 Everettia species in Sabah obtained from BORNEENSIS collection, Universiti Malaysia Sabah. The collection lot reference number, number of specimens in each collection lot, and the geographic coordinates of the specimens were included in the table.

Additional File 2. Results of ModelTest for each partition of DNA sequencing alignment and parameter used in BEAST analysis. Each of the six partitions, namely, codons of COI, namely, 1st, 2nd and 3rd codon positions of COI, 16S rDNA, ITS-1, and 28S rDNA, was tested for molecular evolution via ModelFinder (Kalyaanamoorthy et al., 2017) and partition models (Chernomor et al., 2016) based on the both AIC and BIC that built into IQ-Tree v.1.6.7 (Nguyen et al., 2015; Trifinopoulos et al. 2016). We limited the candidate models to the six models that are available in MrBayes analysis, namely, JC, F81, K80, HKY, SYM, and GTR.

Additional File 3. A zipped folder consists of input files and outputs of Bayesian (BA) and Maximum Likelihood (ML) analysis. The input files and outputs of Bayesian (BA) and Maximum Likelihood (ML) analysis for each of two different best-fit substitution models selected by BIC and AIC criteria, respectively. The phylogenies for each of the analyses were summarised in the word document file.

Additional File 4. A zipped folder consists of input files and outputs of BEAST analysis. A total of four BEAST input XML files for the combinations two different best-fit substitution models (selected by BIC and AIC criteria) and two calibrated models (Yule model vs. Birth-Death 
471

472

473

474

475

476

477

478

479

480

481

482

483

484

485

486

487

488

489

490

491

492

493

494

495

496

497

498

499

500

501

502

503

504

505

506

507

508

509

510

511

512

513

514

515

516

model). The calibrated phylogenies for each of the four analyses were summarised in the word document file.

Additional File 5. Correlations between bioclim variables. Bioclimatic variables were sampled 500 at random locations in Borneo in each of the 19 climatic layers. Collinearity among the 19 climatic variables was evaluated by using pairwise Pearson's $r$ correlation. After the analysis, 12 highly correlated variables $(r>0.8)$ were excluded from MAXENT analysis. The seven climatic variables were used for species distribution modelling, namely, BIO1 Annual Mean Temperature, BIO3 Isothermality, BIO4 Temperature Seasonality, BIO7 Temperature Annual Range, BIO12 Annual Precipitation, BIO15 Precipitation Seasonality, and BIO19 Precipitation of Coldest Quarter.

Additional File 6. Concatenated DNA Data Matrix for 16S, COI, ITS, and 28S Sequences for 73 taxa. DNA sequences alignment in FASTA format. Position 1-501: 16S; Position 502-1059: COI; Position 1060-1869: ITS; and Position 1870-2795: 28S.

\section{References}

Bänfer G, Moog U, Fiala B, Mohamed M, Weising K, Blattners FR. 2006. A chloroplast genealogy of myrmecophytic Macaranga species (Euphorbiaceae) in Southeast Asia reveals hybridization, vicariance and long-distance dispersals. Molecular Ecology 15: 4409-4424.

Barkman TJ, Simpson B. 2001. Origin of high-elevation Dendrochilum species (Orchidaceae) endemic to Mount Kinabalu, Sabah, Malaysia. Systematic Botany 26(3): 658-669.

Beaman JH. 2005. Mount Kinabalu: hotspot of plant diversity in Borneo. Biologiske Skrifter, 55:103-127.

Brandon-Jones D. 1996. The Asian Colobinae (Mammalia: Cercopithecidae) as indicators of Quaternary climate change. Biological Journal of the Linnean Society 59: 327-350.

Brandon-Jones D. 1997. The zoogeography of sexual dichromatism in the Bornean grizzled sureli, Presbytis comata (Desmarest, 1822). Sarawak Museum Journal 50: 177-200.

Beck J, Rüdlinger CM. 2014. Currently available data on Borneo geometrid moths do not provide evidence for a Pleistocene rainforest refugium. Raffles Bulletin of Zoology 62 : 822830

Bird MI, Taylor D, Hunt C. 2005. Palaeoenvironments of insular Southeast Asia during the Last Glacial Period: A savanna corridor in Sundaland? Quaternary Science Reviews 24:2228-2242.

de Bruyn M, Stelbrink B, Morley RJ, Hall R, Carvalho GR, Cannon CH, van den Bergh G, Meijaard E, Metcalfe I, Boitani L, Maiorano L. 2014. Borneo and Indochina are major 
517

518

519

520

521

522

523

524

525

526

527

528

529

530

531

532

533

534

535

536

537

538

539

540

541

542

543

544

545

546

547

548

549

550

551

552

553

554

555

556

557

558

559

560

561

562

evolutionary hotspots for Southeast Asian biodiversity. Systematic Biology, 63(6), pp.879901.

Cannon CH, Morley RJ, Bush ABG. 2009. The current refugial rainforests of Sundaland are unrepresentative of their biogeographic past and highly vulnerable to disturbance. Proceedings of the National Academy of Sciences of the United States of America, 106:1118811193.

Chan CL, Barkman TJ. 1997. A new species of Calanthe (Orchidaceae: Epidendroideae: Arethuseae) from Mount Kinabalu, Sabah. Sandakania, 9:27-34.

Chen J-M, Poyarkov Jr NA, Suwannapoom C, Lathrop A, Wu Y-, Zhou W-W, Yuan Z-Y, Jina JQ, Chen H-M, Liu H-Q, Nguyen TQ, Nguyen SN, Duong TV, Eto K, Nishikawa K, Matsui M, Orlov NL, Stuart BL, Brown RM, Rowley JJL, Murphy RW, Wang Y-Y. 2018. Largescale phylogenetic analyses provide insights into unrecognized diversity and historical biogeography of Asian leaf-litter frogs, genus Leptolalax (Anura: Megophryidae)." Molecular phylogenetics and evolution 124: 162-171.

Chernomor O, von Haeseler A, Minh BQ. 2016. Terrace aware data structure for phylogenomic inference from supermatrices. Systematic Biology 65: 997-1008.

Chua VL, Smith BT, Burner RC, Rahman MA, Lakim M, Prawiradilaga DM, Moyle RG, Sheldon FH. 2017. Evolutionary and ecological forces influencing population diversification in Bornean montane passerines. Molecular phylogenetics and evolution 113: 139-149.

Cockburn PF. 1978. Flora. In: Kinabalu, Summit of Borneo. Edited by (Luping M, Chin N, Dingley ER. Sabah Society Monograph, Kota Kinabalu, 179-198.

Collenette P. 1963. A physiographic classification of North Borneo. Journal of Geography 17:28-33.

Cottam M, Hall R, Sperber C, Armstrong R. 2010. Pulsed emplacement of the Mount Kinbalu granite, northern Borneo. Journal of the Geological Society 167:49-60.

Davison A .2002. Land snails as a model to understand the role of history and selection in the origins of biodiversity. Population Ecology 44:129-136.

Douris V, Cameron RAD, Rodakis GC, Lecanidou R. 1998. Mitochondrial phylogeography of the land snail Albinaria in Crete: Long-term geological and short-term vicariance effects. Evolution 52:116-125.

Drummond AJ, Rambaut A. 2007. BEAST: Bayesian evolutionary analysis by sampling trees. BMC evolutionary biology 7(1), 214.

Fick SE, Hijmans RJ. 2017. WorldClim 2: new 1-km spatial resolution climate surfaces for global land areas. International Journal of Climatology 37(12), 4302-4315. 
563

564

565

566

567

568

569

570

571

572

573

574

575

576

577

578

579

580

581

582

583

584

585

586

587

588

589

590

591

592

593

594

595

596

597

598

599

600

601

602

603

604

605

606

607
Fiorentino V, Salomone N, Manganelli G, Giusti F .2010. Historical biogeography of Tyrrhenian land snails: The Marmorana-Tyrrheniberus radiation (Pulmonata, Helicidae). Molecular Phylogenetics and Evolution 55:26-37.

Folmer O, Black M, Hoeh W, Litz R, Vrijenhoek R (1994) DNA primers for amplification of mitochondrial cytochrome c oxidase subunit I from diverse metazoan invertebrates. Molecular Marine Biology and Biotechnology 3:294-299.

Gathorne-Hardy FJ, Syaukani, Davies RG, Eggleton P, Jones DT. 2002. Quaternary rainforest refugia in south-east Asia: using termites (Isoptera) as indicators. Biological Journal of the Linnean Society 75: 453-466.

Grismer LL, Wood Jr PL, Aowphol A, Cota M, Grismer MS, Murdoch ML, Aguilar C, Grismer JL. 2016. Out of Borneo, again and again: biogeography of the Stream Toad genus Ansonia Stoliczka (Anura: Bufonidae) and the discovery of the first limestone cave-dwelling species. Biological Journal of the Linnean Society, 120(2), pp.371-395.

Hall R .2013. The palaeogeography of Sundaland and Wallacea since the Late Jurassic. Journal of Limnology, 72 (2): 1-17

Hall TA. 1999. BioEdit: A user-friendly biological sequence alignment editor and analysis program for windows 95/98/NT. Nucleic Acids Symposium Series 41:95-98.

Hausdorf B, Hennig C. 2004. Does vicariance shape biotas? Biogeographical tests of the vicariance model in the north-west European land snail fauna. Journal of Biogeography 31:1751-1757.

Hausdorf B, Hennig C. 2006. Biogeographical tests of the vicariance model in Mediterranean land snails. Journal of Biogeography 337:1202-1211.

Hillis DM, Dixon MT. 1991. Ribosomal DNA: Molecular evolution and phylogenetic inference. The Quarterly Review of Biology 66:411-435.

Holland BS, Cowie RH. 2009. Land snail models in island biogeography: A tale of two snails. American Malacological Bulletin 27:59-68.

Holloway JD. 1996. Butterflies and moths. In: Kinabalu: summit of Borneo. Edited by Wong KM, Phillips A, The Sabah Society, Kota Kinabalu, Sabah, Malaysia, 291-314.

Huelsenbeck JP, Ronquist F. 2001. MrBayes: Bayesian inference of phylogeny. Biometrics, 17:754-755.

Hugall A, Moritz C, Moussalli A, Stanisic J. 2002. Reconciling paleodistribution models and comparative phylogeography in the Wet Tropics rainforest land snail Gnarosophia

Peer] reviewing PDF | (2019:09:41728:1:1:CHECK 15 May 2020) 
608

609

610

611

612

613

614

615

616

617

618

619

620

621

622

623

624

625

626

627

628

629

630

631

632

633

634

635

636

637

638

639

640

641

642

643

644

645

646

647

648

649

650

651

652 bellendenkerensis (Brazier 1875). Proceedings of the National Academy of Sciences 99(9): 6112-6117.

Jalil MF, Cable J, Sinyor J, Lackman-Ancrenaz I, Ancrenaz M, Bruford MW, Goossens B. 2008. Riverine effects on mitochondrial structure of Bornean orang-utans (Pongo pygmaeus) at two spatial scales. Molecular Ecology 17:2898-2909.

Kalyaanamoorthy S, Minh BQ, Wong TKF, von Haeseler A, Jermiin LS. 2017. ModelFinder: Fast Model Selection for Accurate Phylogenetic Estimates. Nature Methods 14:587-589.

Ketmaier V, Manganelli G, Tiedemann R, Giusti F. 2010. Peri-Tyrrhenian phylogeography in the land snail Solatopupa guidoni (Pulmonata). Malacologia, 52:81-96.

Kiehl JT, Gent PR .2004. The community climate system model, version 2. Journal of Climate 17: 3666-3682.

Klaus S, Selvandran S, Goh JW, Wowor D, Brandis D, Koller P, Schubart CD, Streit, R, Ng PKL, Yeo DC. 2013. Out of Borneo: Neogene diversification of Sundaic freshwater crabs (Crustacea: Brachyura: Gecarcinucidae: Parathelphusa). Journal of Biogeography 40(1): 6374.

Kokshoorn B, van Schoor M, Erkelens I, Gittenberger E. 2010. Waves of dispersal in islandhopping Chondrina species (Gastropoda, Pulmonata, Chondrinidae). Zoologischer Anzeiger 249: 71-79.

de Laubenfels DJ. 1988. Coniferales. Flora Malesiana Series I, 10:337-453.

Lanfear, R., Frandsen, P. B., Wright, A. M., Senfeld, T., \& Calcott, B. (2016). PartitionFinder 2: new methods for selecting partitioned models of evolution for molecular and morphological phylogenetic analyses. Molecular Biology and Evolution, 34(3), 772-773.

Lee DW, Lowry JB. 1980. Plant speciation on tropical mountains: Leptospermum (Myrtaceae) on Mount Kinabalu, Borneo. Botanical Journal of the Linnean Society 80: 223-242.

Liew T-S, Schilthuizen M, Lakim M .2010. The determinants of land snail diversity along a tropical elevational gradient: insularity, geometry and niches. Journal of Biogeography 37:1071-1078.

Liew T-S, Schilthuizen M, Vermeulen JJ .2009. Systematic revision of the genus Everettia Godwin-Austen, 1891 (Mollusca: Gastropoda: Dyakiidae) in Sabah, Northern Borneo. Zoological Journal of the Linnean Society 157:515-550.

Lim HC, Sheldon FH. 2011. Multilocus analysis of the evolutionary dynamics of rainforest bird populations in Southeast Asia. Molecular Ecology, 20:3414-3438.

Peer) reviewing PDF | (2019:09:41728:1:1:CHECK 15 May 2020) 
653

654

655

656

657

658

659

660

661

662

663

664

665

666

667

668

669

670

671

672

673

674

675

676

677

678

679

680

681

682

683

684

685

686

687

688

689

690

691

692

693

694

695

696

697
Lim HC, Zou F, Taylor SS, Marks BD, Moyle RG, Voelker G, Sheldon FH. 2010. Phylogeny of magpie-robis and shamas (Aves: Turdidae: Copsychus and Trichixos): Implications for island biogeography in Southeast Asia. Journal of Biogeography 37:1894-1906.

Lumadyo E, McCabe R, Harder S, Lee T. 1993. Borneo: a stable portion of the Eurasian margin since the Eocene. Journal of Southeast Asian Earth Sciences, 8(1-4), 225-231.

Mackinnon K, Hatta G, Halim H, Mangalik A. 1996. The Ecology of Kalimantan. Periplus Editions, Singapore.

Mackinnon J, Mackinnon K. 1986. Review of the protected areas system in the Indo-Malayan Realm. IUCN, Gland.

Manthey JD, Moyle RG, Gawin DF, Rahman MA, Ramji MFS, Sheldon FH. 2017. Genomic phylogeography of the endemic Mountain Black-eye of Borneo (Chlorocharis emiliae): montane and lowland populations differ in patterns of Pleistocene diversification. Journal of Biogeography 44(10); 2272-2283.

Merckx VSFT, Hendriks KP, Beentjes KK, Mennes CB, Becking LE, Peijnenburg KTCA, Afendy A, Arumugam N, de Boer H, Biun A, Buang MM, Chen P-P, Chung AYC, Dow R, Feijen FAA, Feijen H, Feijen-van Soest C, Geml J, Geurts R, Gravendeel B, Hovenkamp P, Imbun P, Ipor I, Janssens SB, Jocqué M, Kappes H, Khoo E, Koomen P, Lens F, Majapun RJ, Morgado LN, Neupane S, Nieser N, Pereira JT, Rahman H, Sabran S, Sawang A, Schwallier RM, Shim P-S, Smit H, Sol N, Spait M, Stech M, Stokvis F, Sugau JB, Suleiman M, Sumail S, Thomas DC, van Tol J, Tuh FYY, Yahya BE, Nais J, Repin R, Lakim M, Schilthuizen M. 2015. Evolution of endemism on a young tropical mountain. Nature 524: 347-350.

Miller MA, Pfeiffer W, Schwartz T. 2010. Creating the CIPRES Science Gateway for inference of large phylogenetic trees. In Gateway Computing Environments Workshop (GCE), 2010 (pp. 1-8). IEEE.

Moyle RG, Schilthuizen M, Rahman MA, Sheldon FH. 2005. Molecular phylogenetic analysis of the white-crowned forktail Enicurus leschenaultia in Borneo. Journal of Avian Biology 36: 96-101.

Moyle RG, Taylor SS, Oliveros CH, Lim HC, Haines CL, Rahman MA, Sheldon FH. 2011. Diversification of an endemic Southeast Asian genus: phylogenetic relationships of the spiderhunters (Nectariniidae: Arachnothera). The Auk 128(4): 777-788.

Moyle RG, Manthey JD, Hosner PA, Rahman M, Lakim M, Sheldon FH. 2017. A genome-wide assessment of stages of elevational parapatry in Bornean passerine birds reveals no introgression: implications for processes and patterns of speciation. PeerJ 5: e3335.

Morley RJ. 2012. A review of the Cenozoic palaeoclimate history of Southeast Asia. Biotic evolution and environmental change in Southeast Asia. In Biotic evolution and environmental

Peer) reviewing PDF | (2019:09:41728:1:1:CHECK 15 May 2020) 
698

699

700

701

702

703

704

705

706

707

708

709

710

711

712

713

714

715

716

717

718

719

720

721

722

723

724

725

726

727

728

729

730

731

732

733

734

735

736

737

738

739

740

741 change in Southeast Asia, Gower D, Johnson K, Richardson J, Rosen B, Rüber L, Williams S (eds). Natural History Museum, London 79-114.

Myers N, Mittermeier RA, Mittermeier CG, da Fonseca GAB, Kent J. 2000. Biodiversity hotspots for conservation priorities. Nature, 403:853-858.

Nauheimer L, Boyce PC, Renner SS. 2012. Giant taro and its relatives: a phylogeny of the large genus Alocasia (Araceae) sheds light on Miocene floristic exchange in the Malesian region. Molecular Phylogenetics and Evolution, 63(1): 43-51.

Nguyen L-T, Schmidt HA, von Haeseler A, Minh BQ. 2015. IQ-TREE: A fast and effective stochastic algorithm for estimating maximum likelihood phylogenies. Molecular Biology and Evolution 32: 268-274.

O'Connell KA, Smart U, Smith EN, Hamidy A, Kurniawan N, Fujita MK. 2018. Within-island diversification underlies parachuting frog (Rhacophorus) species accumulation on the Sunda Shelf. Journal of Biogeography 45(4): 929-940.

Palumbi S, Martin A, Romano S, Mcmillan WO, Stice L, Grabowski G. 1991. The Simple Fool's Guide to PCR. University of Hawaii, Honolulu.

Parmakelis A, Pfenninger M, Spanos L, Papagiannakis G, Louis C, Mylonas M. 2005. Inference of a radiation in Mastus (Gastropoda, Pulmonata, Enidae) on the island of Crete. Evolution, 59:991-1005.

Patou ML, Wilting A, Gaubert P, Esselstyn JA, Cruaud C, Jennings AP, Fickel J, Veron G. 2010. Evolutionary history of the Paradoxurus palm civets - a new model for Asian biogeography. Journal of Biogeography 37:2077-2097.

Pfenninger M, Vela E, Jesse R, Arantzazu E, Miren L, Fabio M, Frederic Martinez-Orti. 2010. A Temporal speciation pattern in the western Mediterranean genus Tudorella P. Fischer, 1885 (Gastropoda, Pomatiidae) supports the Tyrrhenian vicariance hypothesis. Molecular Phylogenetics and Evolution 54:427-436.

Phillips SJ, Anderson RP, Schapire RE .2006. Maximum entropy modeling of species geographic distributions. Ecological Modelling190:231-259.

Phillips SJ, Dudík M .2008. Modeling of species distributions with Maxent: new extensions and comprehensive evaluation. Ecography, 31:161-175.

Quek SP, Davies SJ, Ashton PS, Itino T, Pierce N. 2007. The geography of diversification in mutualistic ants: a gene's-eye view into the Neogene history of Sundaland rain forests. Molecular Ecology 16:2045-2062. 
742

743

744

745

746

747

748

749

750

751

752

753

754

755

756

757

758

759

760

761

762

763

764

765

766

767

768

769

770

771

772

773

774

775

776

777

778

779

780

781

782

783

784

785

786
Raheem DC, Schneider S, Böhme M, Vasiliyan D, Prieto J. 2018. The oldest known cyclophoroidean land snails (Caenogastropoda) from Asia. Journal of Systematic Palaeontology 16(15): 1301-1317.

Rowson B, Tattersfield P, Symondson WOC. 2011. Phylogeny and biogeography of tropical carnivorous land-snails (Pulmonata: Streptaxoidea) with particular reference to East Africa and the Indian Ocean. Zoologica Scripta 40:85-98.

Schilthuizen M, Gutteling E, van Moorsel CHM, Welter-Schultes FW, Haase M, Gittenberger E. 2004. Phylogeography of the land snail Albinaria hippolyti (Pulmonata: Clausiliidae) from Crete, inferred from ITS-1 sequences. Biological Journal of the Linnean Society 83:317-326.

Sheldon FH, Lim HC, Moyle RG. 2015. Return to the Malay Archipelago: the biogeography of Sundaic rainforest birds. Journal of Ornithology 156(1): 91-113.

Sheldon FH. 2017. On the biogeography of Sabah's rainforest birds. Sabah Society Journal 33: 31-44.

Smith JMB. 1980. The vegetation of the summit zone of Mount Kinabalu. New Phytologist 84:547-573.

Tanaka H, Roubik DW, Kato M, Liew F, Gunsalam G. 2001. Phylogenetic position of Apis nuluensis of northern Borneo and phylogeography of $A$. cerana as inferred from mitochondrial DNA sequences. Insectes Sociaux 48: 44-51.

Trifinopoulos J, Nguyen LT, von Haeseler A, Minh BQ. 2016. W-IQ-TREE: a fast online phylogenetic tool for maximum likelihood analysis. Nucleic Acids Research, 44(W1): W232W235.

Ueda S, Quek SP, Itioka T, Murase K, Itino T. 2010. Phylogeography of the Coccus scale insects inhabiting myrmecophytic Macaranga plants in Southeast Asia. Population Ecology 52:137146.

Uit de Weerd DR. 2008. Delimitation and phylogenetics of the diverse land-snail family Urocoptidae (Gastropoda: Pulmonata) based on 28S rRNA sequence data: a reunion with Cerion. Journal of Molluscan Studies 74:317-329.

Williams EW, Gardner EM, Harris III R, Chaveerach A, Pereira JT, Zerega N J. 2017. Out of Borneo: biogeography, phylogeny and divergence date estimates of Artocarpus (Moraceae). Annals of botany 119(4): 611-627.

Wong KM. 1998. Patterns in plant endemism and rarity in Borneo and the Malay Peninsula. In: Rare, threatened and endangered floras of Asia and the Pacific rim. Edited by Peng CI, Lowry II PP, Vol. 16. Inst. of Botany, Academia Sinica Monograph Series, TaiwanWWF and IUCN, 139-169.

Peer] reviewing PDF | (2019:09:41728:1:1:CHECK 15 May 2020) 
787 Wronski T, Hausdorf B. 2008. Distribution patterns of land snails in Ugandan rain forests

Wurster CM, Bird MI, Bull ID, Creed F, Bryant C, Dungait JAJ, Paz V. 2010. Forest contraction in north equatorial Southeast Asia during the Last Glacial Period. Proceedings of the National Academy of Sciences of the United States of America, 107:15508-15511.

Xing L, Ross AJ, Stilwell JD, Fang J, McKellar RC. 2019. Juvenile snail with preserved soft tissue in mid-Cretaceous amber from Myanmar suggests a cyclophoroidean (Gastropoda) ancestry. Cretaceous Research 93: 114-119. 


\section{Table $\mathbf{1}$ (on next page)}

Species, voucher specimens, location information, and GenBank accession number.

Abbreviation for repositories of voucher specimens: BORNEENSIS at Universiti Malaysia Sabah, the Sabah Parks Museum (SP), Jaap Jan Vermeulen's private collection (JJ), Leiden, Naturalis Biodiversity Center, Leiden (RMNH, ZMA), the Natural History Museum, London (BMNH), Mohammad Effendi Marzuki's private collection (ME), and Yansen Chen's private collection (YSC). 


\begin{tabular}{|c|c|c|c|c|c|c|c|}
\hline no. & species & Voucher specimens & Location & $16 S$ & COI & $28 S$ & ITS \\
\hline 1 & Quantula striata & BOR/MOL 13939 & Singapore & FJ160646 & FJ160693 & JQ180190 & FJ160732 \\
\hline 2 & Quantula striata & BOR/MOL 7905 & Labuan Island, Sabah, Malaysia & MN564843 & MN564863 & - & MN596180 \\
\hline 3 & Everettia sp. 1 & YC collection & Benualawas, Meratus Range, South Kalimantan, Indonesia & MN564844 & MN564864 & & MN596181 \\
\hline 4 & Everettia sp. 1 & YC collection & Benualawas, Meratus Range, South Kalimantan, Indonesia & MN564845 & MN564865 & & MN596182 \\
\hline 5 & Everettia sp. 1 & YC collection & Benualawas, Meratus Range, South Kalimantan, Indonesia & MN564846 & MN564866 & MN619663 & MN596183 \\
\hline 6 & Everettia sp. 2 & YC collection & Beramba, Meratus Range, South Kalimantan, Indonesia & MN564847 & MN564867 & MN619665 & MN596184 \\
\hline 7 & Everettia sp. 2 & YC collection & Beramba, Meratus Range, South Kalimantan, Indonesia & MN564848 & MN564868 & MN619666 & MN596185 \\
\hline 8 & Everettia sp. 3 & YC collection & Desa Tongka, North Barito, Centre Kalimantan, Indonesia & MN564849 & MN564869 & & MN596186 \\
\hline 9 & Everettia sp. 4 & V12508 & Sangkulirang, East Kalimantan, Indonesia & - & JQ180089 & JQ180188 & - \\
\hline 10 & Everettia sp. 5 & V12504 & Sangkulirang, East Kalimantan, Indonesia & - & JQ180090 & JQ180189 & - \\
\hline 11 & Everettia sp. 6 & BOR/MOL 5480 & Lanjak-Entimau Wildlife Sanctuary, Sarawak, Malaysia & JQ180055 & JQ180088 & - & JQ180114 \\
\hline 12 & Everettia sp. 7 & BOR/MOL 5481 & Lanjak-Entimau Wildlife Sanctuary, Sarawak, Malaysia & JQ180054 & JQ180086 & JQ180186 & JQ180112 \\
\hline 13 & Everettia sp. 7 & BOR/MOL 5481 & Lanjak-Entimau Wildlife Sanctuary, Sarawak, Malaysia & - & JQ180087 & - & JQ180113 \\
\hline 14 & $\begin{array}{l}\text { Everettia } \\
\text { baramensis }\end{array}$ & WM collection & Mulu National Park, Sarawak, Malaysia & JQ180053 & JQ180085 & JQ180185 & JQ180111 \\
\hline 15 & Everettia algaia & ME collection & Niah Cave, Miri, Sarawak & - & MN564870 & MN619668 & MN596187 \\
\hline 16 & $\begin{array}{l}\text { Everettia corrugata } \\
\text { corrugata }\end{array}$ & BOR/MOL 12936 & Mt. Kinabalu northwestern slope, 3000 m (S142), Sabah, Malaysia & FJ160619 & FJ160666 & - & FJ160710 \\
\hline 17 & $\begin{array}{l}\text { Everettia corrugata } \\
\text { corrugata }\end{array}$ & BOR/MOL 12828 & Mt. Kinabalu southern slope, 3400 m (S16), Sabah, Malaysia & FJ160621 & FJ160668 & JQ180164 & FJ160711 \\
\hline 18 & $\begin{array}{l}\text { Everettia corrugata } \\
\text { williamsi }\end{array}$ & BOR/MOL 12935 & Mt. Kinabalu southeastern slope, 3100 m (S69A), Sabah, Malaysia & FJ160622 & FJ160669 & JQ180165 & FJ160712 \\
\hline 19 & $\begin{array}{l}\text { Everettia corrugata } \\
\text { williamsi }\end{array}$ & BOR/MOL 12935 & Mt. Kinabalu southeastern slope, 3100 m (S69B), Sabah, Malaysia & JQ180041 & JQ180074 & JQ180166 & JQ180106 \\
\hline 20 & Everettia dominiki & BOR/MOL 12861 & $\begin{array}{l}\text { Mt. Kinabalu southwesthern slope, } 2100 \mathrm{~m} \text { (S100), Sabah, } \\
\text { Malaysia }\end{array}$ & FJ160598 & FJ160649 & JQ180180 & FJ160696 \\
\hline 21 & Everettia dominiki & BOR/MOL 12800 & Mt. Tambuyukon eastern slope 2200 m (S102), Sabah, Malaysia & FJ160599 & FJ160650 & JQ180181 & FJ160697 \\
\hline 22 & Everettia dominiki & BOR/MOL 12838 & Mt. Kinabalu southeastern slope, 3100 m (S68), Sabah, Malaysia & FJ160606 & FJ160657 & JQ180182 & FJ160700 \\
\hline 23 & Everettia dominiki & BOR/MOL 12860 & Mt. Kinabalu southwesthern slope, 3100 m (S87), Sabah, Malaysia & FJ160607 & FJ160658 & JQ180183 & FJ160701 \\
\hline 24 & Everettia planispira & BOR/MOL 14115 & Tawau Hills Park, Tawau, Sabah, Malaysia & FJ160595 & FJ160647 & JQ180177 & FJ160694 \\
\hline 25 & Everettia monticola & BOR/MOL 12798 & Mt. Kinabalu Southern slope, 1700 m (S32), Sabah, Malaysia & FJ160596 & FJ160648 & JQ180179 & FJ160695 \\
\hline 26 & Everettia interior & BOR/MOL 12879 & Batu Tinagas, Sapulut, Sabah, Malaysia & FJ160637 & FJ160684 & - & FJ160725 \\
\hline 27 & Everettia interior & BOR/MOL 12871 & Batu Sanaron, Sapulut, Sabah, Malaysia & FJ160638 & FJ160685 & JQ180170 & FJ160726 \\
\hline 28 & Everettia jasilini & BOR/MOL 12846 & Mt. Kinabalu rortheastern slope, 3100 m (S80), Sabah, Malaysia & FJ160617 & FJ160664 & JQ180174 & FJ160708 \\
\hline 29 & Everettia jasilini & BOR/MOL 12810 & Mt. Kinabalu rorthwestern slope, $2800 \mathrm{~m}$ (S140), Sabah, Malaysia & FJ160618 & FJ160665 & JQ180175 & FJ160709 \\
\hline 30 & Everettia safriei & BOR/MOL 12929 & Mt. Kinabalu rortheastern slope, 3300 m (S79), Sabah, Malaysia & FJ160614 & FJ160663 & JQ180176 & FJ160707 \\
\hline 31 & Everettia safriei & BOR/MOL 12855 & Mt. Kinabalu southeastern slope, 2900 m (S66), Sabah, Malaysia & JQ180049 & JQ180082 & - & JQ180109 \\
\hline 32 & $\begin{array}{l}\text { Everettia } \\
\text { klemmatanica }\end{array}$ & BOR/MOL 14097 & Mt. Kinabalu southern slope, $1700 \mathrm{~m}$, Sabah, Malaysia & FJ160611 & FJ160660 & - & FJ160704 \\
\hline 33 & $\begin{array}{l}\text { Everettia } \\
\text { klemmatanica }\end{array}$ & $\mathrm{BOR} / \mathrm{MOL}$ & Mahua, Crocker Range, $1200 \mathrm{~m}$, Sabah, Malaysia & JQ180039 & JQ180073 & JQ180163 & JQ180105 \\
\hline 34 & Everettia lapidini & SP 12924 & $\begin{array}{l}\text { Mt. Kinabalu southwesthern slope, Marai Parai, } 1700 \mathrm{~m} \text {, } \\
\text { (SP12924), Sabah, Malaysia }\end{array}$ & FJ160645 & FJ160692 & JQ180168 & FJ160731 \\
\hline 35 & $\begin{array}{l}\text { Everettia } \\
\text { layanglayang }\end{array}$ & BOR/MOL 4578 & Mt. Kinabalu northwestern slope, 1800 m, Sabah, Malaysia & FJ160624 & FJ160671 & - & FJ160714 \\
\hline 36 & $\begin{array}{l}\text { Everettia } \\
\text { layanglayang }\end{array}$ & BOR/MOL 4486 & Mt. Kinabalu southern slope, $2300 \mathrm{~m}$ (S11), Sabah, Malaysia & FJ160626 & FJ160673 & - & FJ160716 \\
\hline 37 & $\begin{array}{l}\text { Everettia } \\
\text { layanglayang }\end{array}$ & SP 12907 & Mount Alab, Crocker Range, 1800 m (SP12907?), Sabah, Malaysia & FJ160644 & FJ160691 & - & FJ160730 \\
\hline 38 & $\begin{array}{l}\text { Everettia } \\
\text { layanglayang }\end{array}$ & BOR/MOL 12808 & Mt. Kinabalu southern slope, Mesilau, 2500 m, Sabah, Malaysia & JQ180042 & JQ180075 & JQ180167 & JQ180107 \\
\hline 39 & $\begin{array}{l}\text { Everettia } \\
\text { paulbasintali }\end{array}$ & BOR/MOL 6399 & Tawau Hills Park, Tawau, Sabah, Malaysia & FJ160613 & FJ160662 & JQ180171 & FJ160706 \\
\hline 40 & $\begin{array}{l}\text { Everettia } \\
\text { paulbasintali }\end{array}$ & BOR/MOL 12821 & Tabin Wildlife Reserve (HQ), Lahad Data, Sabah, Malaysia & FJ160642 & FJ160689 & JQ180172 & FJ160729 \\
\hline 41 & $\begin{array}{l}\text { Everettia } \\
\text { paulbasintali }\end{array}$ & BOR/MOL 13011 & Luasing, INIKEA site, Tawau, Sabah, Malaysia & MN564850 & MN564871 & MN619669 & MN596188 \\
\hline 42 & $\begin{array}{l}\text { Everettia } \\
\text { paulbasintali }\end{array}$ & BOR/MOL 13315 & Imbak Crayon Conservation Area, Telupid, Sabah, Malaysia & MN564851 & MN564872 & MN619670 & MN596189 \\
\hline 43 & $\begin{array}{l}\text { Everettia } \\
\text { paulbasintali }\end{array}$ & BOR/MOL 13320 & Imbak Crayon Conservation Area, Telupid, Sabah, Malaysia & MN564852 & - & MN619671 & MN596190 \\
\hline 44 & $\begin{array}{l}\text { Everettia } \\
\text { paulbasintali }\end{array}$ & BOR/MOL 13844 & Mount Silam, 600 m, Lahad Data, Sabah, Malaysia & - & - & - & MN596191 \\
\hline 45 & Everettia subconsul & BOR/MOL 12813 & Mt. Tambuyukon eastern slope, $1100 \mathrm{~m}$ (S114), Sabah, Malaysia & FJ160629 & FJ160676 & - & FJ160719 \\
\hline
\end{tabular}




\begin{tabular}{|c|c|c|c|c|c|c|c|}
\hline 46 & Everettia subconsul & SP & Ulu Membakut, Crocker Range, Sabah, Malaysia & FJ160630 & FJ160677 & JQ180154 & FJ160720 \\
\hline 47 & Everettia subconsul & $\mathrm{BOR} / \mathrm{MOL}$ & Danum Valley, Lahad Datu, Sabah, Malaysia & FJ160639 & FJ160686 & - & FJ160727 \\
\hline 48 & Everettia subconsul & SP & Nalapak Substesen, Kinabalu Kinabalu Park,, Sabah, Malaysia & FJ160640 & FJ160687 & - & FJ160728 \\
\hline 49 & Everettia subconsul & BOR/MOL 6488 & Gaya Island, Kota Kinabalu, Sabah, Malaysia & FJ160634 & FJ160681 & JQ180155 & FJ160722 \\
\hline 50 & Everettia subconsul & BOR/MOL 6492 & Crocker Range Park, Keningau HQ, 800 m, Sabah, Malaysia & MN564853 & MN564873 & - & MN596192 \\
\hline 51 & Everettia subconsul & $\mathrm{BOR} / \mathrm{MOL}$ & Danum Valley, Lahad Datu, Sabah, Malaysia & JQ180027 & JQ180061 & JQ180156 & JQ180095 \\
\hline 52 & Everettia subconsul & BOR/MOL 13936 & Kampung Magnin, Kudat, Sabah, Malaysia & JQ180028 & JQ180062 & - & JQ180096 \\
\hline 53 & Everettia subconsul & BOR/MOL 12868 & Kiansom, Crocker Range, Sabah, Malaysia & JQ180029 & JQ180063 & - & JQ180097 \\
\hline 54 & Everettia subconsul & BOR/MOL 12820 & Imbak Crayon Conservation Area, Telupid, Sabah, Malaysia & JQ180031 & JQ180065 & - & JQ180099 \\
\hline 55 & Everettia subconsul & SP & Tahubang,Mount Kinabalu, Sabah, Malaysia & - & JQ180066 & - & JQ180100 \\
\hline 56 & Everettia subconsul & SP & Kinosolopon, Kimanis, Crocker range, Sabah, Malaysia & JQ180033 & JQ180068 & JQ180157 & JQ180102 \\
\hline 57 & Everettia subconsul & BOR/MOL 12823 & Poring, Mount Kinabalu (600 m), Sabah, Malaysia & JQ180034 & JQ180069 & - & JQ180103 \\
\hline 58 & Everettia subconsul & BOR/MOL 14108 & Meliau Range, Sabah, Malaysia & JQ180035 & JQ180070 & JQ180158 & - \\
\hline 59 & Everettia subconsul & BOR/MOL 6485 & Lumaku, Sabah, Malaysia & JQ180038 & JQ180072 & JQ180160 & - \\
\hline 60 & Everettia subconsul & BOR/MOL 6783 & Sepanggar Island, Sabah, Malaysia & MN564854 & MN564874 & - & MN596193 \\
\hline 61 & Everettia subconsul & BOR/MOL 8852 & Gaya Island, Sabah, Malaysia & MN564855 & MN564875 & & MN596194 \\
\hline 62 & Everettia subconsul & BOR/MOL 8926 & Sayap, Mt. Kinabalu, 800 m, Sabah, Malaysia & MN564856 & MN564876 & $\begin{array}{l}\text { MN6196/2 } \\
-\end{array}$ & MN596195 \\
\hline 63 & Everettia subconsul & BOR/MOL 9246 & Melalap, Crocker Range, 400 m, Sabah, Malaysia & MN564857 & MN564877 & - & - \\
\hline 64 & Everettia subconsul & BOR/MOL 13018 & Inobong, Crocker Range, $300 \mathrm{~m}$, Sabah, Malaysia & MN564858 & MN564878 & 9673 & MN596196 \\
\hline 65 & Everettia themis & SP 12599 & TBC Tower, Crocker Range, 1400 m (SP12599), Sabah, Malaysia & FJ160623 & FJ160670 & JQ180161 & FJ160713 \\
\hline 66 & Everettia themis & $\mathrm{BOR} / \mathrm{MOL}$ & Mt. Kinabalu southern slope, 1900 m, Sabah, Malaysia & FJ160628 & FJ160675 & JQ180162 & FJ160718 \\
\hline 67 & Everettia subconsul & BOR/MOL 13056 & Banggi Island, Sabah, Malaysia & MN564859 & MN564879 & 6161067 & MN596197 \\
\hline 68 & Everettia subconsul & BOR/MOL 13140 & Banggi Island, Sabah, Malaysia & MN564860 & MN564880 & & MN596198 \\
\hline 69 & Everettia jucunda & BOR/MOL 12870 & Klias, Beaufort, Sabah, Malaysia & FJ160635 & FJ160682 & $\begin{array}{l}\text { MN6196/5 } \\
\text { JQ180153 }\end{array}$ & FJ160723 \\
\hline 70 & Everettia jucunda & $\mathrm{BOR} / \mathrm{MOL}$ & Tiga Island, Sabah, Malaysia & FJ160636 & FJ160683 & - & FJ160724 \\
\hline 71 & Everettia jucunda & BOR/MOL 7916 & Labuan Island, Sabah, Malaysia & MN564861 & MN564881 & & MN596199 \\
\hline 72 & Everettia jucunda & BOR/MOL 8648 & Kuraman Island, Sabah, Malaysia & MN564862 & MN564882 & & MN596200 \\
\hline 73 & Everettia jucundior & $\mathrm{BOR} / \mathrm{MOL}$ & Tawau Hills Park, Tawau, Sabah, Malaysia & FJ160612 & FJ160661 & $\begin{array}{l}\text { MN6196// } \\
\text { JQ180173 }\end{array}$ & FJ160705 \\
\hline
\end{tabular}




\section{Figure 1}

The distribution of selected taxa and specimens in Borneo for phylogenetic analysis.

The numbers in parentheses refer to specimen numbers of Table 1.

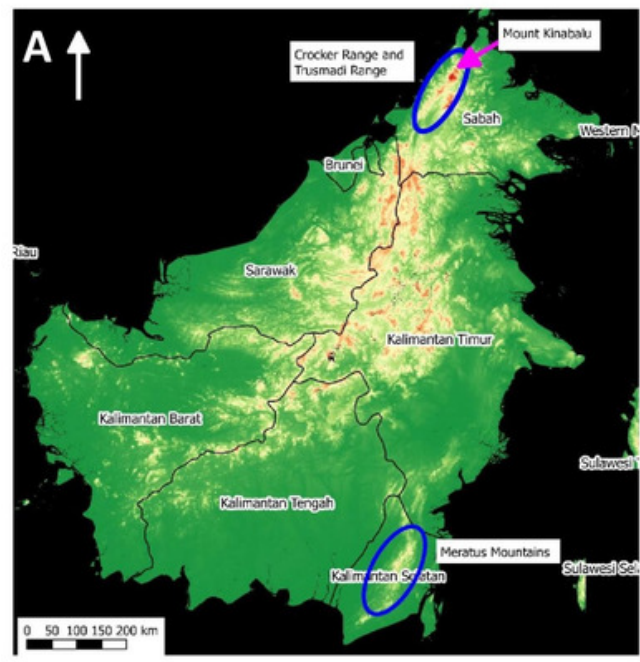

Elevation (a.s.I.)

- $<00 \mathrm{~m}$

501- $1000 \mathrm{~m}$

$1001-1500 \mathrm{~m}$

$1501-2500 \mathrm{~m}$

$>2500 \mathrm{~m}$

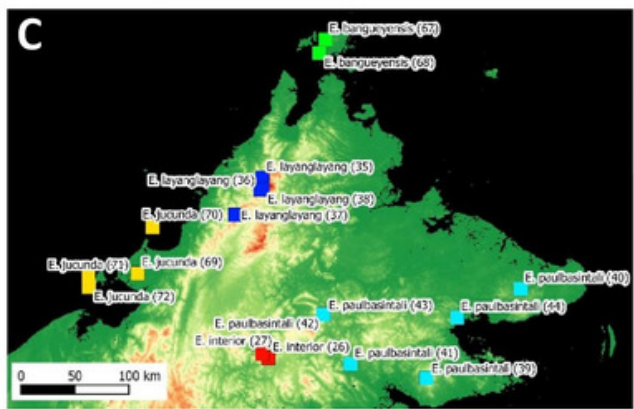

- Everettia bangueyensis

- Everettia interior

Everettia jucunda

- Everettia layanglayang

- Everettia paulbasintali

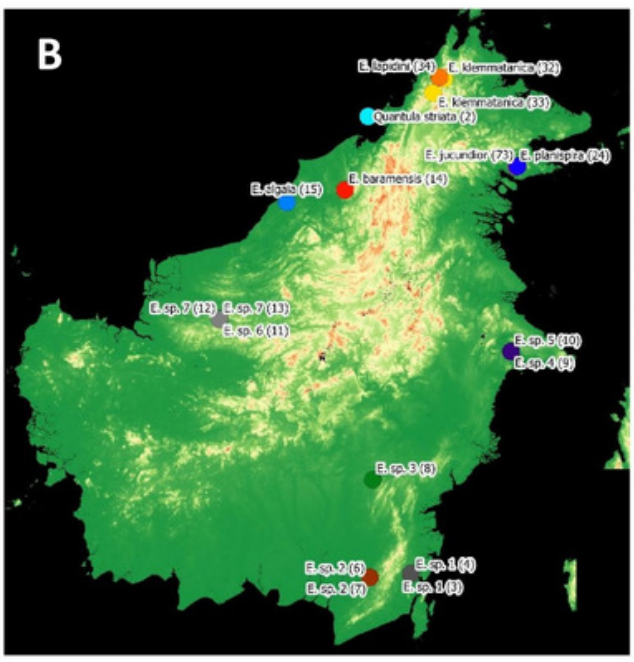

Legend

Species

- Everettia baramensis

- Everettia jucundior

Everettia klemmatanica

- Everettia lapidini

- Everettia planispira

- Everettia sp. 1

- Everettia sp. 2

- Everettia sp. 3

- Everettia sp. 4

- Everettia sp. 5

- Everettia sp. 6

Everettia sp. 7

- Everretia algaia

Quantula striata

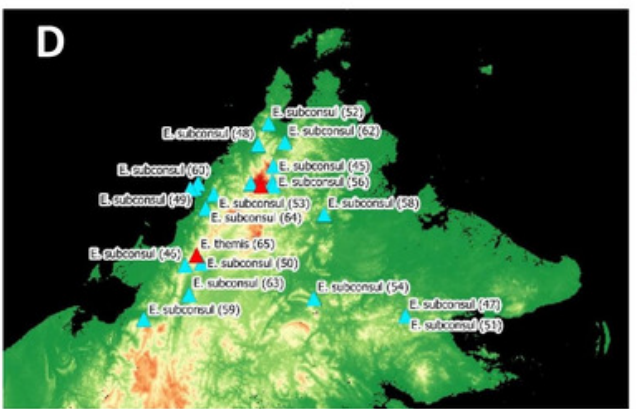

Everettia subconsu

Everettia themis 
Figure 2

The distribution of selected Everettia species and specimens of Mount Kinabalu, Sabah for phylogenetic analysis.

The numbers in parentheses refer to specimen numbers of Table 1. 


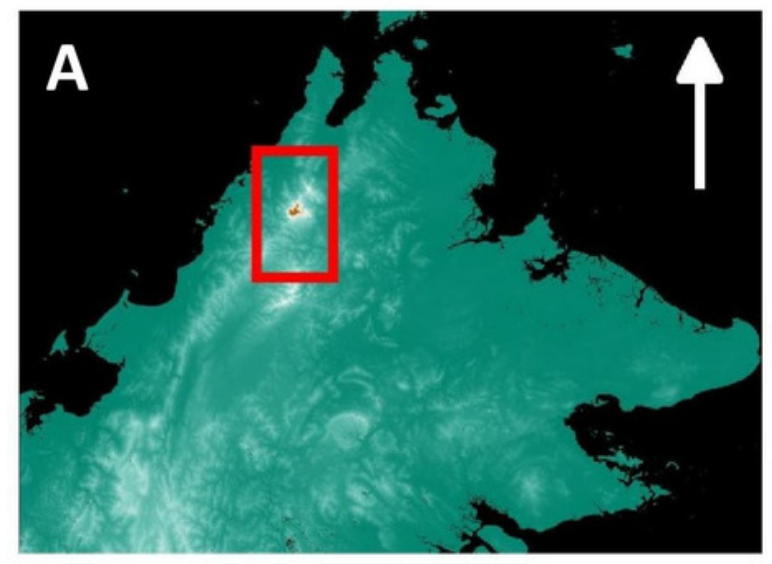

\section{Legend}

\section{Elevation}

$<1500 \mathrm{~m}$

$\square 1501-2500 \mathrm{~m}$

2501 - $3000 \mathrm{~m}$

3001 - $3500 \mathrm{~m}$

3501 - 4100 m

\section{Legend \\ Species}

- Everettia c. corrugata

- Everettia c. williamsi

$\diamond$ Everettia dominiki

B

$01234 \mathrm{~km}$
E. c. corrugata (16)

E. dominiki (20) E. dominiki (23)
E. dominiki (21)

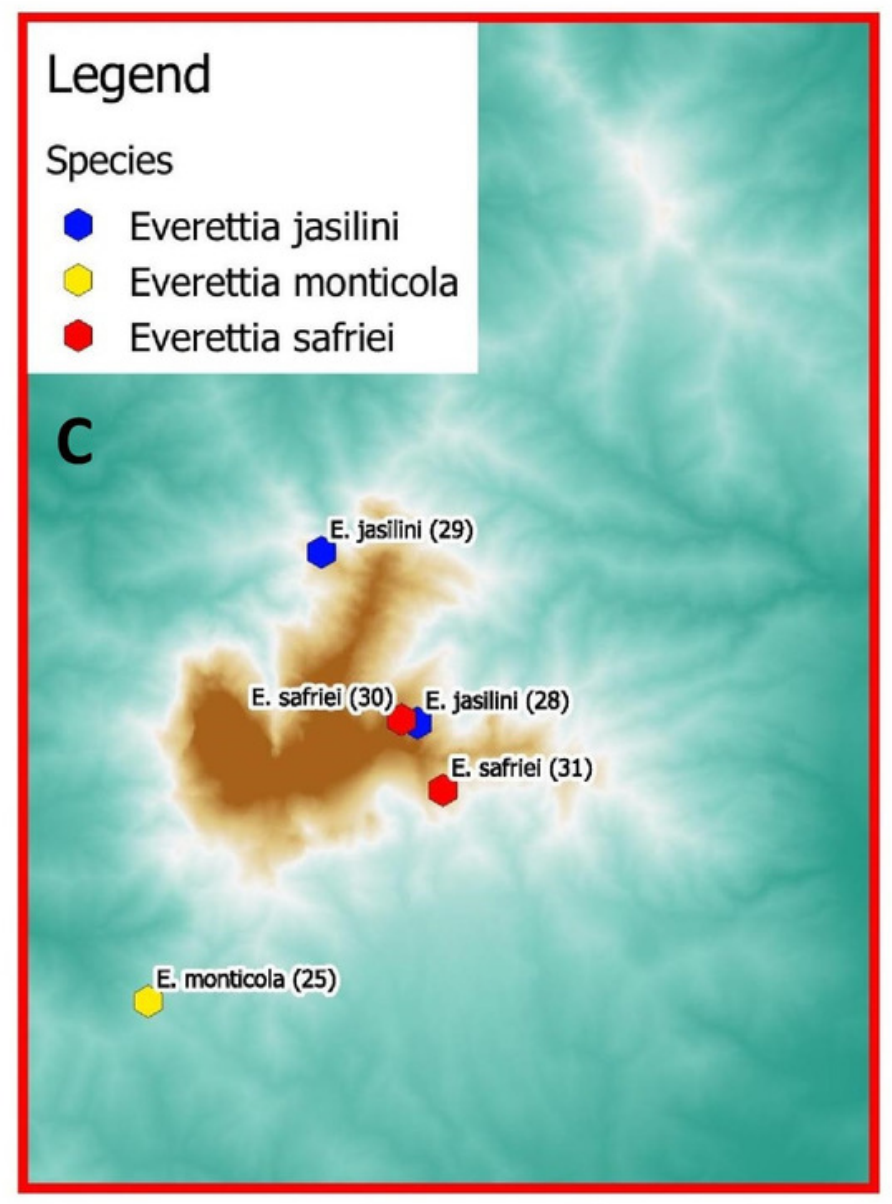




\section{Figure 3}

Contemporary distribution records, estimated habitat suitability area of present and Last Glacial Maximum (LGM) bioclimatic conditions for Everettia safriei, E. jasilini, E. corrugata corrugata, and E. C. [i

From left to right: Distribution records of Everettia species, gathered from BORNEENSIS Mollusca Collection around Mount Kinabalu; Contemporary suitable areas in Borneo for the species based on species distribution modelling using MAXENT with seven bioclimatic variables, and projected Last Glacial Maximum (LGM) suitable areas in Borneo for the species based on species distribution modelling using MAXENT with the same seven bioclimatic variables of CCSM. 
Distribution Records in Sabah
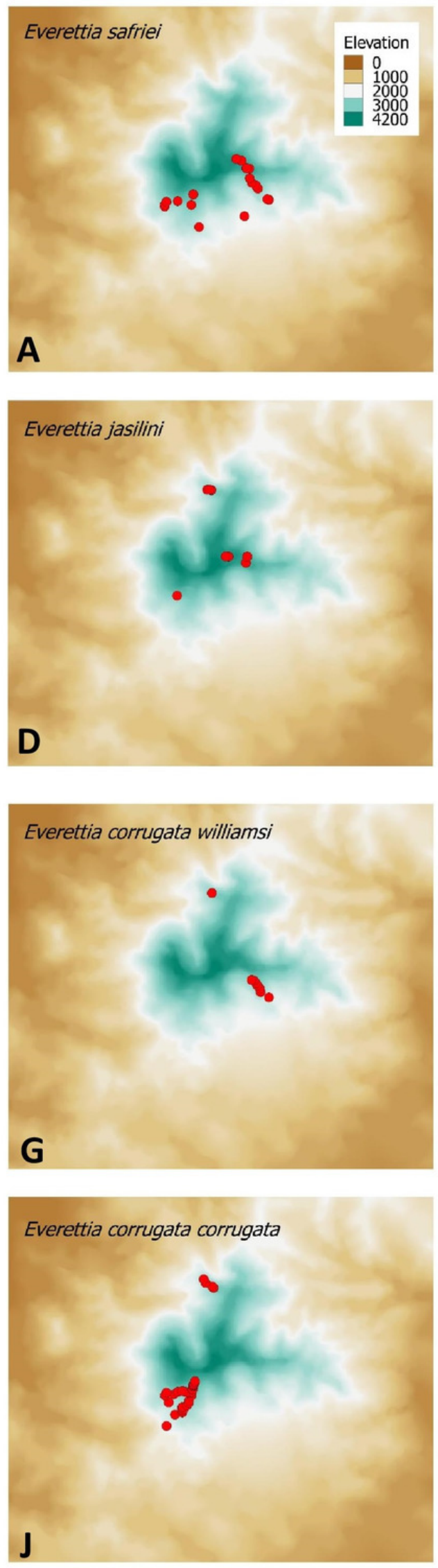

SDM Present
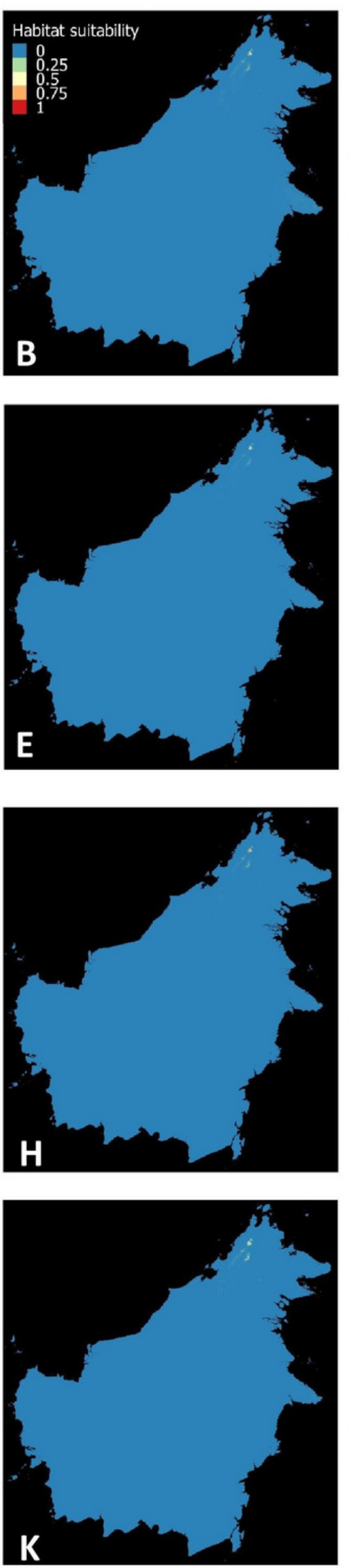

SDM LGM
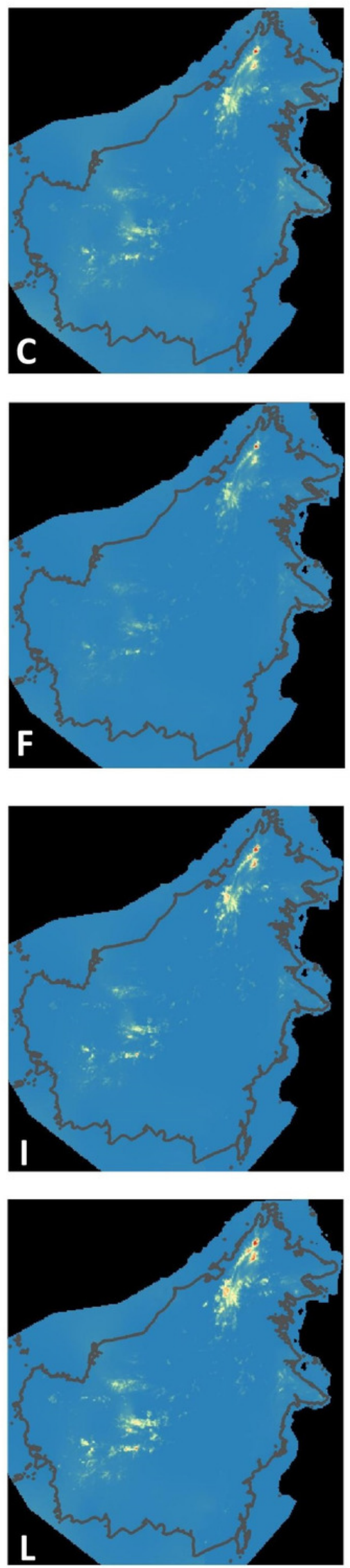


\section{Figure 4}

Contemporary distribution records, estimated habitat suitability area of present and Last Glacial Maximum (LGM) bioclimatic conditions for Everettia layanglayang, $E$. dominiki, E. lapidini, and E. monticola i

From left to right: Distribution records of Everettia species, gathered from BORNEENSIS Mollusca Collection around Mount Kinabalu and Crocker Range; Contemporary suitable areas in Borneo for the species based on species distribution modelling using MAXENT with seven bioclimatic variables, and projected Last Glacial Maximum (LGM) suitable areas in Borneo for the species based on species distribution modelling using MAXENT with the same seven bioclimatic variables of CCSM. 
Distribution Records in Sabah
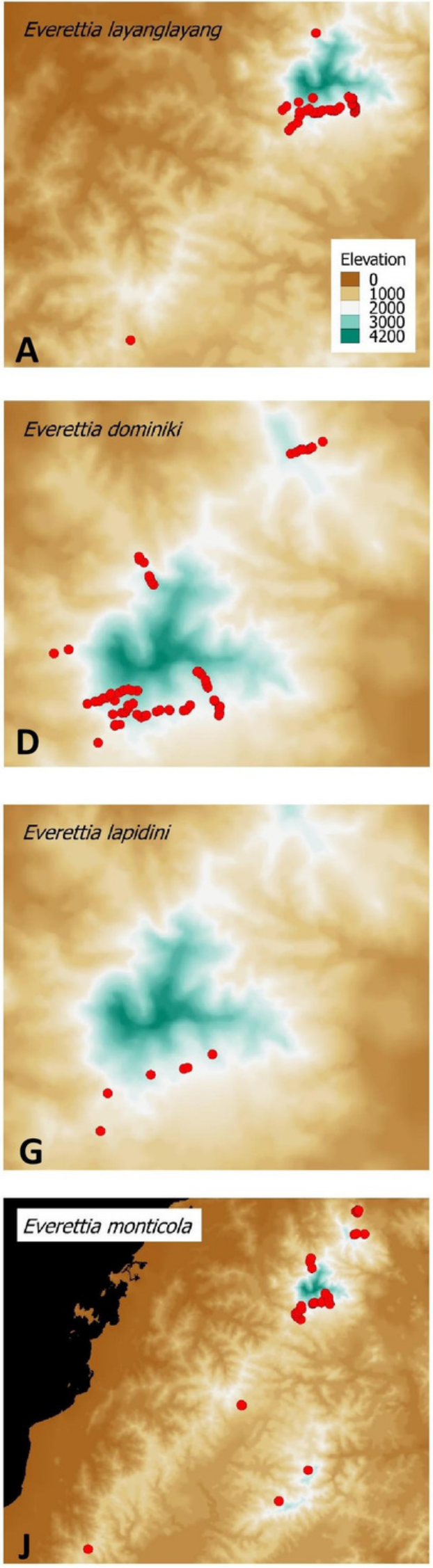

SDM Present
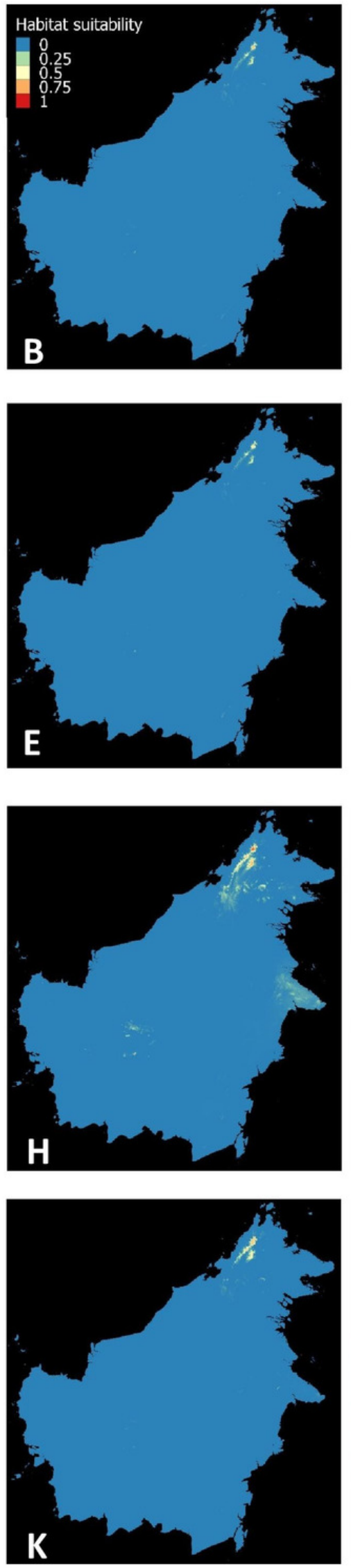

SDM LGM
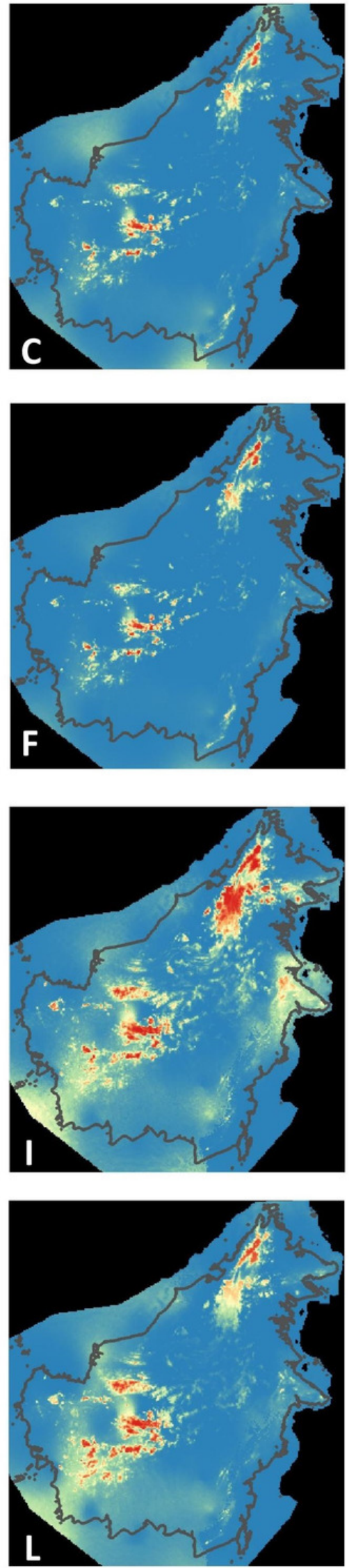


\section{Figure 5}

Contemporary distribution records, estimated habitat suitability area of present and Last Glacial Maximum (LGM) bioclimatic conditions for Everettia paulbasintali, E. occidentalis, E. jucunda, and E. [i]interior [

From left to right: Distribution records of Everettia species, gathered from BORNEENSIS Mollusca Collection in Sabah; Contemporary suitable areas in Borneo for the species based on species distribution modelling using MAXENT with seven bioclimatic variables, and projected Last Glacial Maximum (LGM) suitable areas in Borneo for the species based on species distribution modelling using MAXENT with the same seven bioclimatic variables of CCSM. 
Distribution Records in Sabah
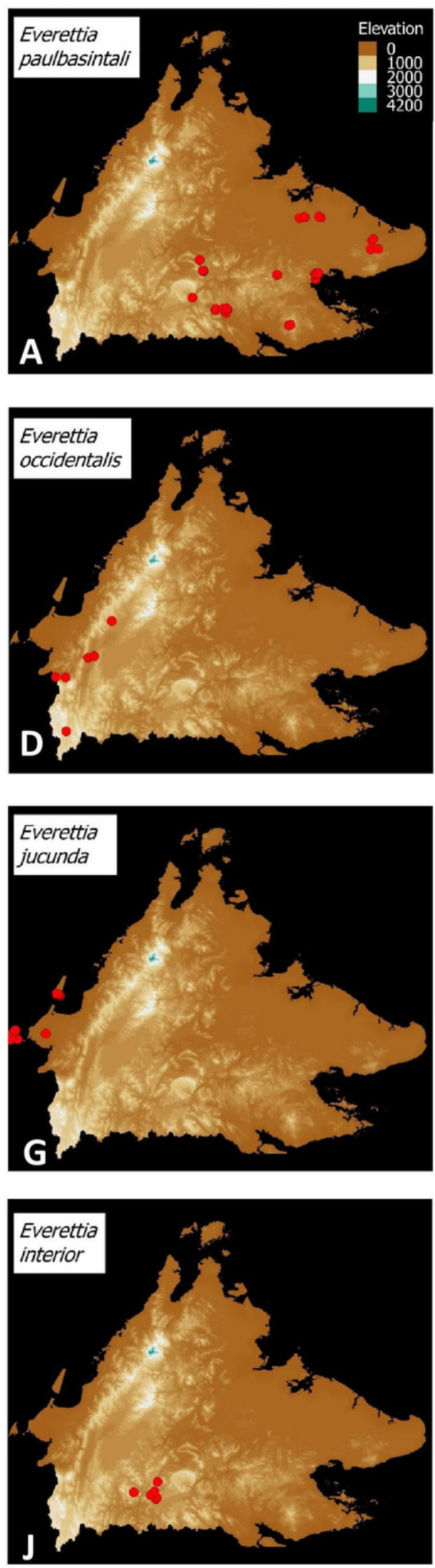

SDM Present
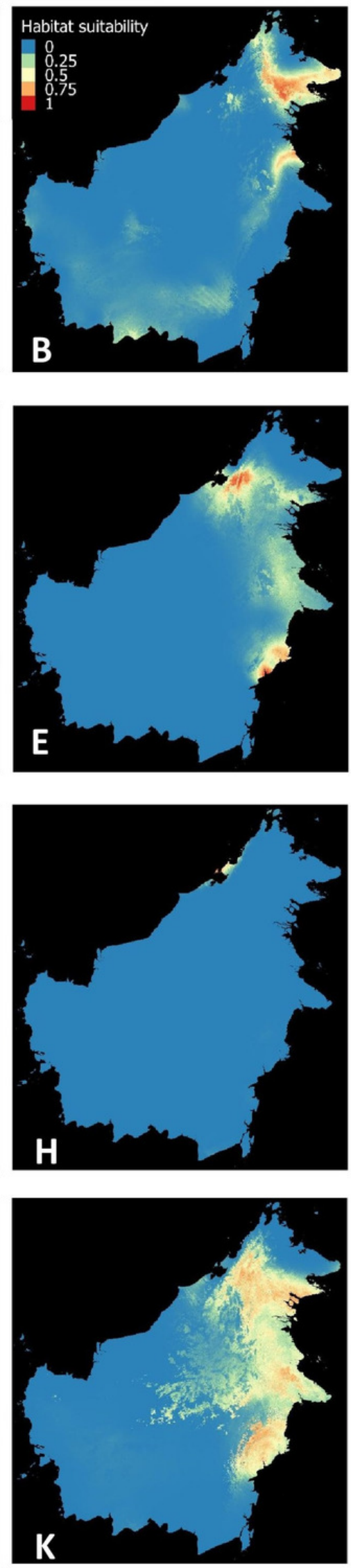

SDM LGM
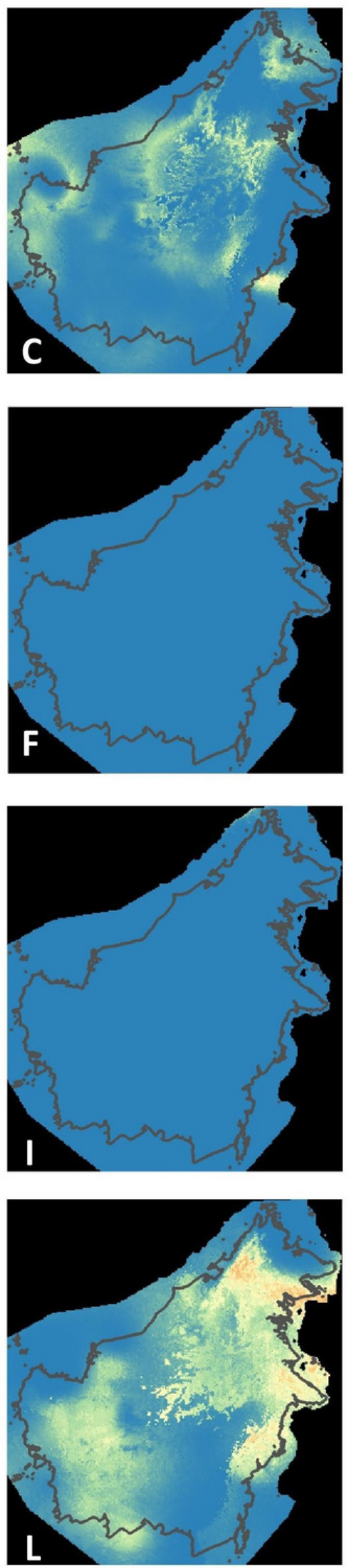


\section{Figure 6}

Contemporary distribution records, estimated habitat suitability area of present and Last Glacial Maximum (LGM) bioclimatic conditions for Everettia jucundior, E. planispira, and $E$. subconsul in Borneo.

From left to right: Distribution records of Everettia species, gathered from BORNEENSIS Mollusca Collection in Sabah; Contemporary, suitable areas in Borneo for the species based on species distribution modelling using MAXENT with seven bioclimatic variables, and projected Last Glacial Maximum (LGM) suitable areas in Borneo for the species based on species distribution modelling using MAXENT with the same seven bioclimatic variables of CCSM. 
Distribution Records in Sabah
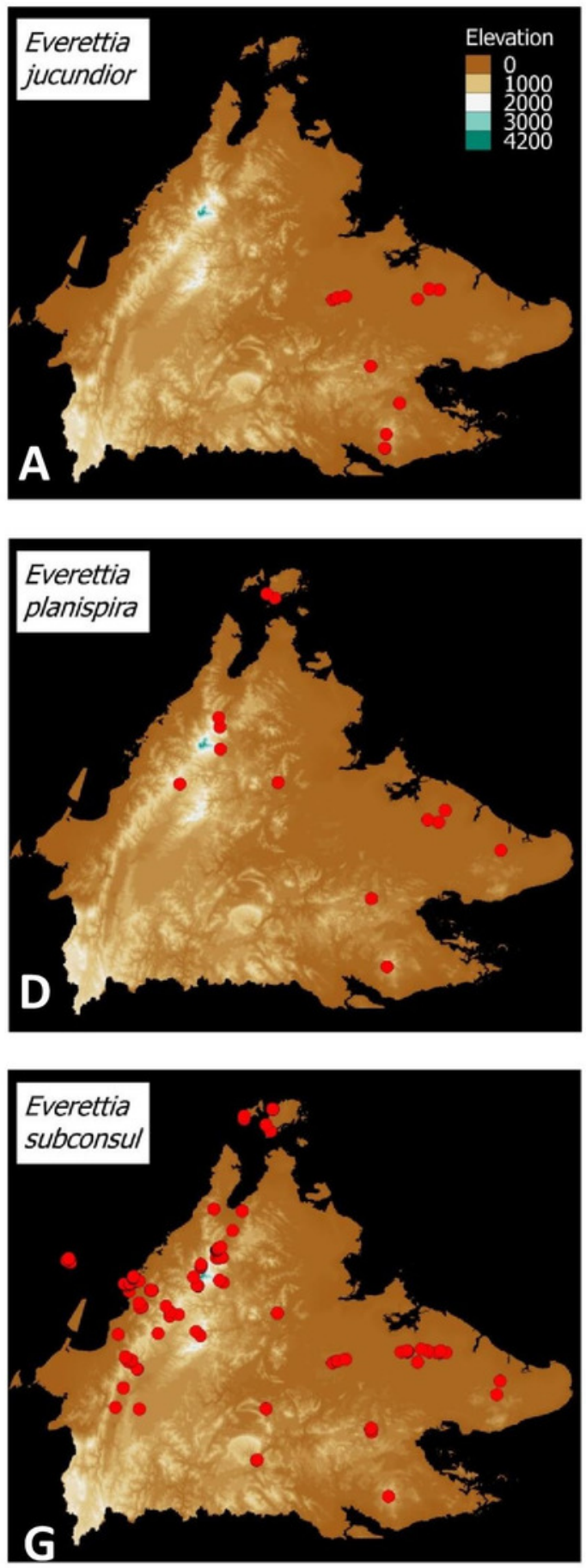

SDM Present
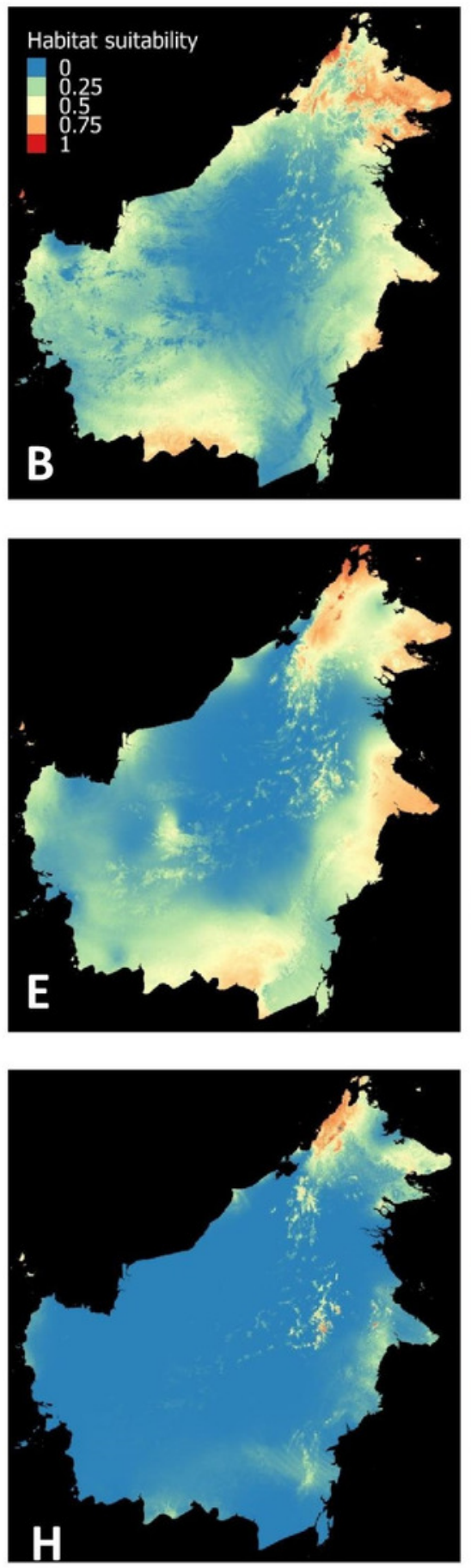

SDM LGM
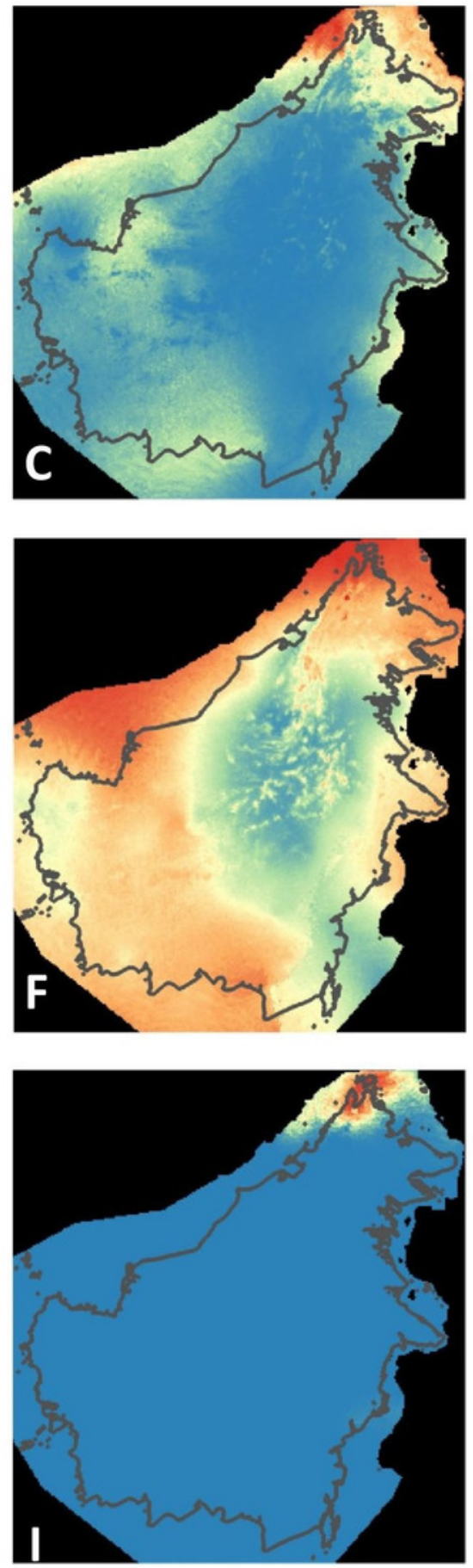


\section{Figure 7}

The phylogeny of 25 Everettia species with Quantula striata as outgroup.

Bayesian inference $50 \%$ majority-rule consensus trees based on the concatenated dataset consisting of parts of 28S, ITS-1, COI, and 16S. Bayesian posterior probabilities and bootstrap support after 1000 maximum likelihood replicates are shown above and below the branches of the nodes. The font and colour of the taxa name on the tree indicate the distribution of the species. The colour panels next to the taxa names indicated the lowest elevation distributional (Left) and highest elevation distributional (Right) of the species. The number after the taxa name specimen number of Table 1, Figs 1 and 2. 


\section{Legend for font and colour of the taxa name}

Sabah Everettia species

Sabah Everettia species endemic to Crocker Range

Sabah Everettia species endemic to Mount Kinabalu

\section{Kalimantan Everettia species}

Sarawak Everettia species

$\underline{\text { Outgroup taxa }}$

\section{Legend Sabah Everettia species elevational distribution}

Lowest elevational distribution (Left)

$$
\begin{aligned}
< & 1000 \mathrm{~m} \\
& 1001-2000 \mathrm{~m} \\
> & 2001 \mathrm{~m}
\end{aligned}
$$

highest elevational distribution (Right)

$<1500 \mathrm{~m}$

$1501-3000 m$

$>3001 \mathrm{~m}$
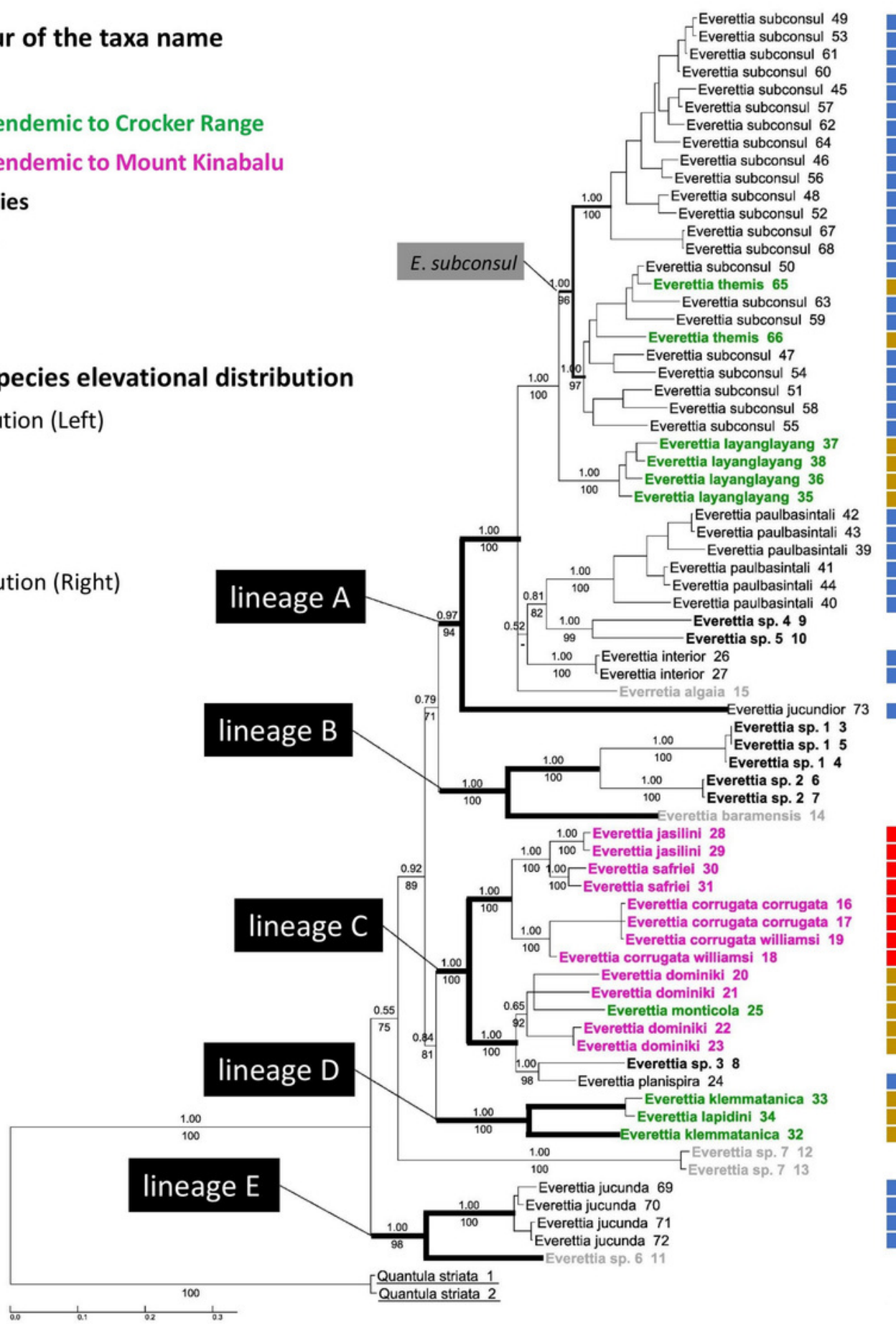


\section{Figure 8}

The chronogram for Everettia species in Borneo obtained from divergence time estimation using BEAST.

The divergence times (in million years ago, Mya) of the major lineages are shown as values on the chronogram branches: bold values are mean ages and values between brackets represent the $95 \%$ Highest Posterior Density (HPD) interval (i.e. bar values). The arrow indicates the calibration points. The font and colour of the taxa name on the tree indicate the distribution of the species. The colour panels next to the taxa names indicated the lowest elevation distributional (Left) and highest elevation distributional (Right) of the species. The number after the taxa name specimen number of Table 1, Figs 1 and 2. Bottom panel shows the paleogeography of Borneo adapted from (Hall, 2013): $25 \mathrm{Ma}$ - Late Oligocene. A large part of Borneo was submerged, except the area of West Kalimantan; $20 \mathrm{Ma}$ - Early Miocene. Increase of land area in central Borneo and uplift of the central Borneo mountains; $15 \mathrm{Ma}$ - Middle Miocene. Further uplift in central Borneo and northern Borneo, much of present-day Sabah was below or close to sea level and probably with a minor elevated range of hills at the position of the Crocker range; $10 \mathrm{Ma}$ - Late Miocene. Further uplift of the central part of Borneo, propagation of land area in eastern and northern Borneo with gradual rise and widening of the Crocker Range, and uplift of Meratus mountains in South Kalimantan. Borneo was now a significantly emergent and elevated area.; $5 \mathrm{Ma}$ - Early Pliocene. Further propagation of land area in eastern, southern, and northern Borneo. 


\section{Legend for font and colour of the taxa name}

Sabah Everettia species

Sabah Everettia species endemic to Crocker Range

Sabah Everettia species endemic to Mount Kinabalu

Kalimantan Everettia species

Sarawak Everettia species

Outgroup taxa
Everettia_subconsul 49 Everettia subconsul 46 Everettia_subconsul_62 Everettia_subconsul_64 Everettia_subconsul 52 Everettia subconsul 67

Everettia subconsul 50

Everettia themis 65 Everettia_subconsul_ 51 Everettia_subconsul 54

Everettia layanglayang 37 Everettia_layanglayang_35 Everettia paulbasintali 43 Everettia paulbasintali_39 Everettia_paulbasintali_40 Lowest elevational distribution (Left) < $1000 \mathrm{~m}$

- $1001-2000 \mathrm{~m}$

> $2001 \mathrm{~m}$

highest elevational distribution (Right)

- $<1500 \mathrm{~m}$

$1501-3000 m$

> $3001 \mathrm{~m}$

Everettia sp 5

Everettia jucundior 73 Everettia jasilini_29 -Everettia_safriei_30

Everettia dominiki 23 Everettia dominiki 20 Everretia_algaia_15 Everettia_interior_27

Elevational distribution

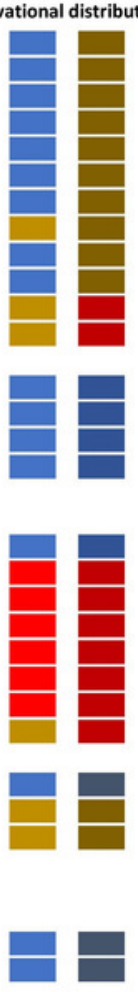
Everettia_corrugata_corrugata_17 Everettia corrugata williamsi_19 Everettia_monticola_25 Everettia_sp_3 8 Everettia_planispira_24 - Everettia_klemmatanica_32 Everettia_lapidini_34

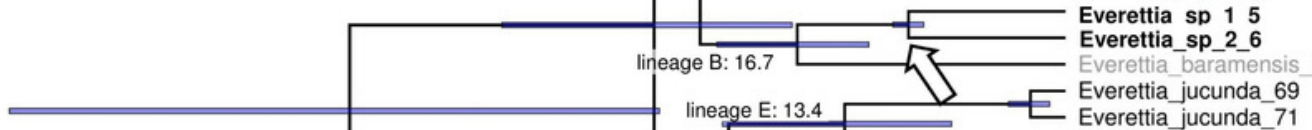

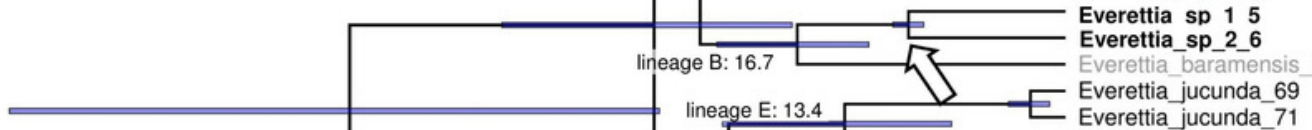

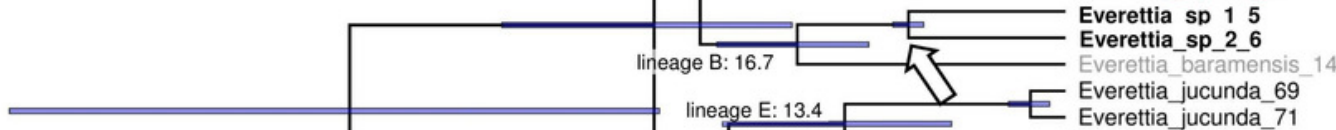
Everettia_jucunda_71 Everettia SP-7-12 Quantula striata 1

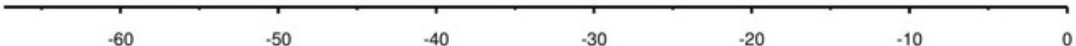

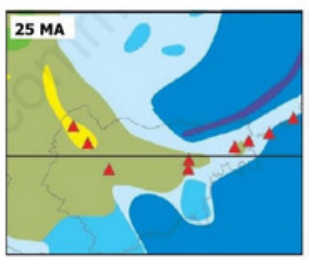

$20 \mathrm{MA}$

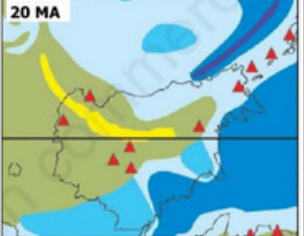

5 MA
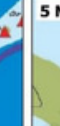

1

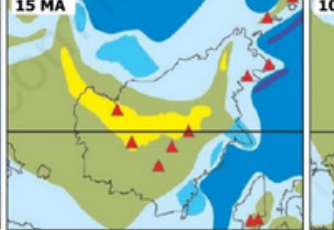

10 MA
A VOLCANOES HIGHLANDS

LAND

SHALLOW SEA

CARBONATE

PLATFORMS

- DEEP SEA

- TRENCHES 